\title{
The Development of Midlatitude Cirrus Models for MODIS Using FIRE-I, FIRE-II, and ARM In Situ Data
}

\author{
Shama L. NAsiri, * Bryan A. BaUm, ${ }^{+}$Andrew J. Heymsfield, \#nng Yang, @ Míchaei R. Poellot, \& \\ DAVID P. KRATZ, ${ }^{+}$AND YONGXIANG HU ${ }^{+}$ \\ ${ }^{*}$ Cooperative Institute for Meteorological Satellite Studies, University of Wisconsin-Madison, Madison, Wisconsin \\ ${ }^{+}$NASA Langley Research Center, Hampton, Virginia \\ \#National Center for Atmospheric Research,** Boulder, Colorado \\ @ Goddard Earth Science and Technology Center. University of Maryland. Baltimore County, Baltimnre, Maryland \\ \&University of North Dakota, Grand Forks, North Dakota
}

(Manuscript received 4 December 2000, in final form 1 June 2001)

\section{ABSTRACT}

Detailed in situ data from cirrus clouds have been collected during dedicated field campaigns, but the use of the size and habit distribution data has been lagging in the development of more realistic cirrus scattering models. In this study, the authors examine the use of in situ cirrus data collected during three field campaigns to develop more realistic midlatitude cirrus microphysical models. Data are used from the First International Satellite Cloud Climatology Project (ISCCP) Regional Experiment (FIRE)-I (1986) and FIRE-II (1991) campaigns and from a recent Atmospheric Radiation Measurement (ARM) Program campaign held in March-April of 2000. The microphysical models are based on measured vertical distributions of both particle size and particle habit and are used to develop new scattering models for a suite of moderate-resolution imaging spectoradiometer (MODIS) bands spanning visible, near-infrared, and infrared wavelengths. The sensitivity of the resulting scattering properties to the underlying assumptions of the assumed particle size and habit distributions are examined. It is found that the near-infrared bands are sensitive not only to the discretization of the size distribution but also to the assumed habit distribution. In addition, the results indicate that the effective diameter calculated from a given size distribution tends to be sensitive to the number of size bins that are used to discretize the data and also to the ice-crystal habit distribution.

\section{Introduction}

The general approach for inferring cirrus optical and microphysical properties from satellite imagery is to compare measured satellite radiances with the results of radiative transfer calculations for various conditions of viewing geometry, solar illumination, and cloud macrophysical and microphysical properties. With this approach, the retrieved cirrus properties depend on the single-scattering properties of the cirrus models used in the analyses. In turn, the single-scattering properties depend on the assumed cirrus microphysical properties, for example, distributions of cirrus particle sizes and shapes (or habits). As new cirrus cloud observations become available, the cirrus models used in the forward calculations need periodic reevaluation. The primary goal of this study is to document improvements

** The National Center for Atmospheric Research is sponsored by the National Science Foundation.

Corresponding author address: Shaima L. Nasiri, CIMSS, 1225 W. Dayton St.. Madison, WI 53706.

E-mail: shaima.nasiri@ssec.wisc.edu in the development of single-scattering properties for a variety of midlatitude cirrus clouds. The cirrus models are based upon measurements of midlatitude cirrus clouds collected during various field experiments such as the First International Satellite Cloud Climatology Project Regional Experiment (FIRE): FIRE-I and FIRE-II in 1986 and 1991, respectively, and the Department of Energy (DoE) Atmospheric Radiation Measurement (ARM) Program intensive operational period (IOP) in 2000 .

The effort to improve the cirrus models is prompted in part by recent research discussing the importance of cirrus size distribution and particle habits on satellite imager-based visible and near-infrared reflectances (e.g., Knap et al. 1999; Rolland et al. 2000). New cirrus in situ datasets are now available that permit detailed examination of the vertical variability of both particle size and habit. Another motivation for developing new cirrus models is a desire to merge the improved analyses of in situ data with improvements in the development of single-scattering properties of randomly oriented, complex ice-crystal habits such as plates, bullet rosettes, aggregates, and columns.

Recent studies point to the importance of ice-crystal 
TABLE 1. Cloud-top and cloud-base temperatures for in situ data cases.

\begin{tabular}{lcc}
\hline \hline Date & $\begin{array}{c}\text { Cloud-top temperature } \\
\left({ }^{\circ} \mathrm{C}\right)\end{array}$ & $\begin{array}{c}\text { Cloud-base temperature } \\
\left({ }^{\circ} \mathrm{C}\right)\end{array}$ \\
\hline & FIRE-I (1986) & \\
$22 \mathrm{Oct}$ & -37 & -15 \\
$25 \mathrm{Oct}$ & -34 & -15 \\
$28 \mathrm{Oct}$ & -37 & -20 \\
$1 \mathrm{Nov}$ & -44 & -17 \\
$2 \mathrm{Nov}$ & -43 & -20 \\
& FIRE-II (1991) & \\
$25 \mathrm{Nov}$ & -55 & -32 \\
$26 \mathrm{Nov}$ & -55 & -22 \\
$5 \mathrm{Dec}$ & -65 & -39 \\
& ARM $(2000)$ & \\
$9 \mathrm{Mar}$ & -50 & -30 \\
$13 \mathrm{Mar}$ & -50 & -20 \\
\hline
\end{tabular}

habit in retrievals of ice water path, particle size, and optical depth in cirrus clouds. The dependence of retrieved optical thickness on crystal habit has been demonstrated by Mischenko et al. (1996), Doutriaux-Boucher et al. (2000), and others. One of the most complete in situ radiation measurement studies was by Francis et al. (1999). They discussed aircraft measurements of midlatitude cirrus collected by the Met Office C-130 aircraft during a flight on 9 November 1995 off the east coast of Scotland. In situ microphysical data were obtained within a thin layer of frontal cirrus, together with downwelling filter-band radiometer measurements at $0.87,1.61,3.7,8.55$, and $11 \mu \mathrm{m}$. Banked orbits were flown below the cirrus to sample at scattering angles ranging from $21^{\circ}$ to $127^{\circ}$ relative to the sun. To infer optical thickness and particle size, radiative transfer calculations were presented for monodistributions of five individual crystal habits: randomized polycrystals (Macke et al. 1996), hexagonal columns, hexagonal plates, six-branched bullet rosettes, and aggregates composed of hexagonal columns. For a cirrus cloud composed of a single habit, single-scattering properties were obtained by integrating over size distributions using effective radii (defined as the ratio of total volume to total projected area) ranging from 9.4 to $85.9 \mu \mathrm{m}$. A raytracing technique was employed to derive single-scattering properties of the ice crystals. Francis et al. (1999) found that the cirrus composed of polycrystals produced effective sizes that were consistent with the in situ data across all the wavelengths considered. However, the retrieved $0.87-\mu \mathrm{m}$ optical thicknesses were considerably less than those derived at $11 \mu \mathrm{m}$, implying a problem with the phase function at solar wavelengths for the polycrystal over a wide range of primarily side-scattering angles. Francis et al. (1999) explain that the error in effective size retrieval introduced by the polycrystal overprediction of side scattering is canceled by its underprediction of single-scattering albedo. Francis et al. also note the importance of characterizing realistic cirrus
TABLE 2. Spectral and radiometric characteristics of the Earth $\mathrm{Ob}$ serving System Terra platform MODIS spectral bands used in this study.

\begin{tabular}{ccl}
\hline \hline Band No. & $\begin{array}{c}\text { Central } \\
\text { wavelength } \\
(\mu \mathrm{m})\end{array}$ & Principal absorbing components \\
\hline 1 & 0.65 & $\mathrm{H}_{2} \mathrm{O}, \mathrm{O}_{2} \mathrm{O}_{3}$ \\
6 & 1.64 & $\mathrm{H}_{2} \mathrm{O}, \mathrm{CO}_{2} \mathrm{CH}_{4}$ \\
7 & 2.13 & $\mathrm{H}_{2} \mathrm{O}, \mathrm{CO}_{2} \mathrm{CH}_{4} \mathrm{~N}_{2} \mathrm{O}$ \\
20 & 3.78 & $\mathrm{H}_{2} \mathrm{O}, \mathrm{CO}_{2} \mathrm{CH}_{4}$ \\
26 & 1.38 & $\mathrm{H}_{2} \mathrm{O}$ \\
29 & 8.52 & $\mathrm{H}_{2} \mathrm{O}, \mathrm{O}_{3} \mathrm{CH}_{4} \mathrm{~N}_{2} \mathrm{O}$ \\
31 & 11 & $\mathrm{H}_{2} \mathrm{O}, \mathrm{CO}_{2}$ \\
32 & 12 & $\mathrm{H}_{2} \mathrm{O}, \mathrm{CO}_{2}$ \\
\hline
\end{tabular}

ice particles and show that their retrieved optical thicknesses compared better to theory when a laboratoryderived phase function reported by Volkovitskiy et al. (1980) was employed.

Baran et al. (1999) used the dual-view geometry of alongtrack scanning radiometer (ATSR)-2 data to estimate the most likely dominating crystal shape at 0.87 $\mu \mathrm{m}$. In their study, radiative transfer (RT) calculations were performed for cirrus composed of a single crystal type: hexagonal plates, hexagonal columns, sixbranched bullet rosettes, or randomized polycrystals. The simulated radiances subsequently were compared to selected ATSR-2 data from a tropical convective cirrus case and a midlatitude cirrus case. For the tropical case, the best comparison between the ATSR- 2 data at $0.87 \mu \mathrm{m}$ and RT calculations was obtained for the randomized polycrystal, perhaps due to the lack of enhanced intensity features in the phase function at backscattering angles. For the midlatitude cirrus case, comparison was made between extinction optical depth retrievals using ATSR-2-measured radiances, aircraft measurements of midlatitude cirrus at 0.87 and $11 \mu \mathrm{m}$, and in situ-calculated optical thickness (Francis et al. 1999). It is interesting that the best comparison was obtained using a phase function obtained from laboratory measurements (Volkovitskiy et al. 1980) rather than from the randomized polycrystal. Baran et al. (1999) suggested that the aircraft samples the phase function at mostly side-scattering angles rather than backscattering angles, suggesting that perhaps the polycrystal is less optimal at side-scattering angles.

Given the importance of cirrus microphysics in remote sensing applications, we now turn attention to the current set of operational moderate-resolution imaging spectroradiometer (MODIS) cirrus models (Baum et al. 2000). The microphysical data are derived from the following sources. The cirrostratus and cirrus uncinus distributions are described by Heymsfield (1975), and Heymsfield and Platt (1984) present two modified size distributions typical of warm and cold cirrus clouds and three additional cirrus distributions that represent midlatitude cirrus at temperatures $T=$ $-20^{\circ},-40^{\circ}$, and $-60^{\circ} \mathrm{C}$. The seven size distributions 
TABLE 3. Particle number distributions based on five size bins.

\begin{tabular}{ccccc}
\hline \hline \multirow{2}{*}{$\begin{array}{c}\text { Max } \\
\text { dimension width } \\
(\mu \mathrm{m})\end{array}$} & $\begin{array}{c}\text { Bin- } \\
(\mu \mathrm{m})\end{array}$ & \multicolumn{3}{c}{ Number concentration $\left(\mathrm{L}^{-1} \mu \mathrm{m}^{-1}\right)$} \\
\cline { 3 - 5 } & 20 & $4.4904 \times 10^{-1}$ & $9.2994 \times 10^{-1}$ & $0.0000 \times 10^{\circ}$ \\
15 & 40 & $1.0089 \times 10^{\circ}$ & $4.2441 \times 10^{-1}$ & $1.0792 \times 10^{\circ}$ \\
45 & 400 & $7.6280 \times 10^{-2}$ & $9.8850 \times 10^{-2}$ & $7.2287 \times 10^{-1}$ \\
130 & 100 & FIRE-II & ARM \\
275 & 260 & $2.1286 \times 10^{-2}$ & $1.4585 \times 10^{-2}$ & $4.3616 \times 10^{-2}$ \\
750 & 640 & $1.7600 \times 10^{-3}$ & $1.1579 \times 10^{-4}$ & $3.5373 \times 10^{-3}$ \\
\hline
\end{tabular}

cover a range of cloud microphysical properties and dynamical regimes, for example, production in slowly ascending parcels to $100 \mathrm{~cm} \mathrm{~s}^{-1}$ updrafts. Most of the cirrus were sampied aboard a Cessna Citatioñ jêt ùsiñg three different probes (Heymsfield 1975; Heymsfield and Platt 1984): 1) a forward-scattering spectrometer probe (FSSP) for particle sizes ranging between 2 and $30 \mu \mathrm{m}$ in $2-\mu \mathrm{m}$ intervals; 2 ) a one-dimensional optical array probe (1D-C) to obtain particle sizes between 20 and $300 \mu \mathrm{m}$ in $20-\mu \mathrm{m}$ intervals, and 3) a one-dimensional precipitation probe (1D-P) to size particles between 200 and $3000 \mu \mathrm{m}$ in $200-\mu \mathrm{m}$ intervals. A Formvar (polyvinyl formal-a plastic) replicator was employed to provide data on particle habits for crystals less than $200 \mu \mathrm{m}$ in size; larger particles tended to break up upon impact.

Given the limitations of the 1D-C and 1D-P measurements, the size spectra for the MODIS cirrus models in Baum et al. (2000) are limited to five discrete size regions. When the maximum dimension $D$ is small ( $D$ $<70 \mu \mathrm{m}$ ), that is, for small ice crystals, the percentage of ice crystals within the size region is assumed to be composed of $50 \%$ bullet rosettes, $25 \%$ hexagonal plates, and $25 \%$ hollow hexagonal columns. When $D$ is greater than $70 \mu \mathrm{m}$, the percentage of ice crystals within the size region is assumed to be composed of $30 \%$ aggregates, $30 \%$ bullet rosettes, $20 \%$ hexagonal plates, and $20 \%$ hollow hexagonal columns. The mixture of habits in this initial set of cirrus models is a function only of particle size and is invariant between models.

Recent improvements in the instrumentation used to obtain in situ cirrus measurements provide, for the first time, a basis for discussing vertical variability of size and habit distributions. The cirrus measurements from FIRE-II are from a balloonborne ice-crystal replicator (Heymsfield and Miloshevich 1995), which provides high-quality image, size, and concentration information for particles $10 \mu \mathrm{m}$ and above. With this replicator, ice crystals have less of a tendency to break up upon collection because of the slow rise rates $\left(4-5 \mathrm{~m} \mathrm{~s}^{-1}\right)$ of the balloon (Miloshevich and Heymsfield 1997). The cirrus measurements from FIRE-I (Heymsfield et al. 1990; Sassen et al. 1994) and ARM are based on twodimensional crystal cloud (2D-C) and precipitation (2D-P) probe data. The $2 \mathrm{D}-\mathrm{C}$ probe sized particles from 25 to about $1000 \mu \mathrm{m}$ in $25-\mu \mathrm{m}$ increments, and the 2D-P probe sized particles from 100 to above 2000 $\mu \mathrm{m}$ in $100-\mu \mathrm{m}$ increments. The $2 \mathrm{D}-\mathrm{C}$ and, especially, the 2D-P are insufficient to obtain much information on habits, especially for the smaller crystals. For FIREI, habit information was provided through collection of particles directly on oil-coated slides (Sassen et al. 1994). For the ARM campaign, cirrus-particle habit data were provided through use of the SPEC, Inc., cloud particle imager (CPI), which provides detailed imagery of particles, beginning at about $40 \mu \mathrm{m}$ with 2.3- $\mu \mathrm{m}$ resolution.

With recent advances in developing single-scattering properties for ice crystals and the improvements in in situ data from cirrus clouds, it is now possible to develop a)

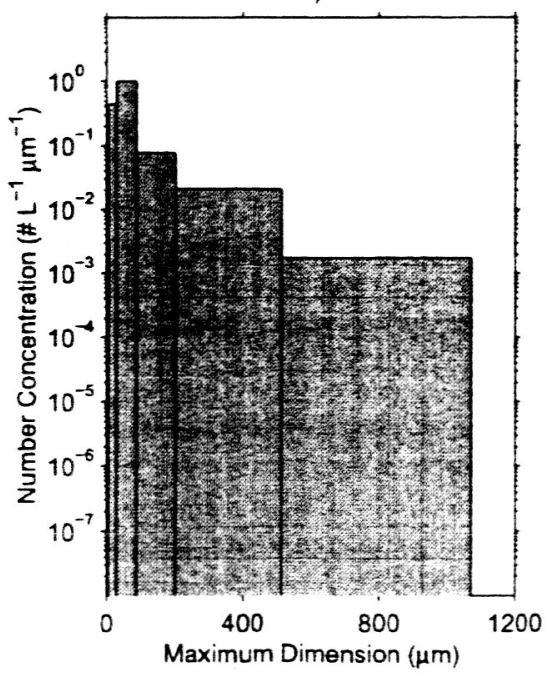

b)

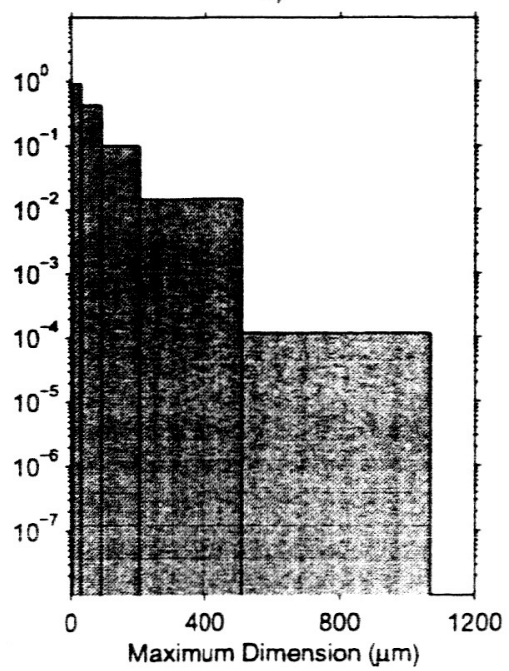

c)

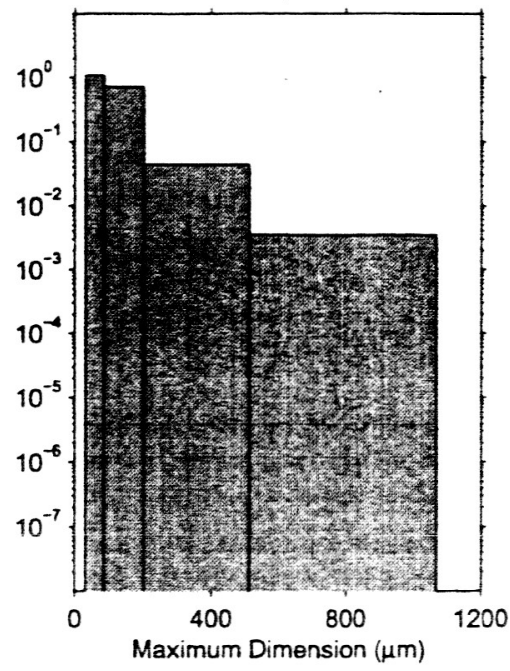

FIG. 1. Size distributions based on five size bins for the (a) FIRE-I, (b) FIRE-II, and (c) ARM cirrus microphysical models described in section 3 


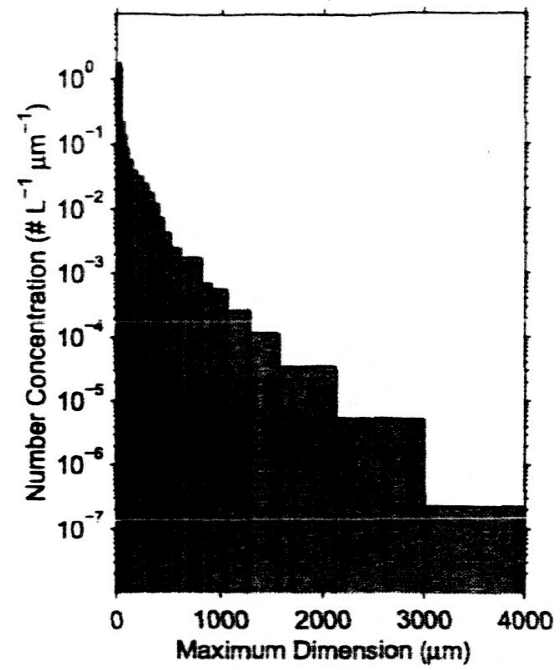

b)

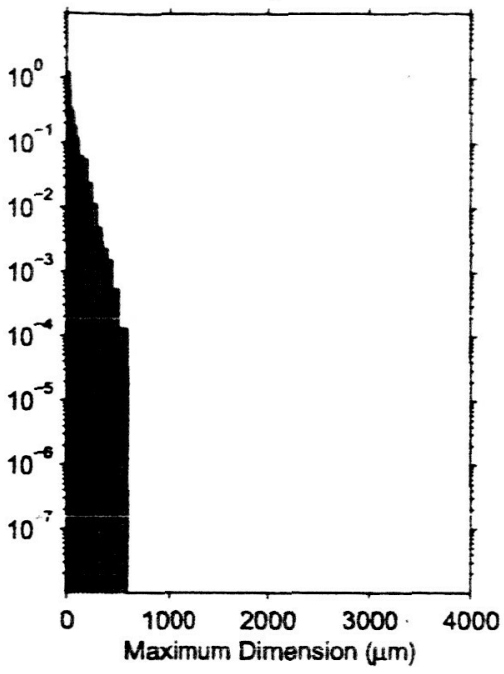

c)

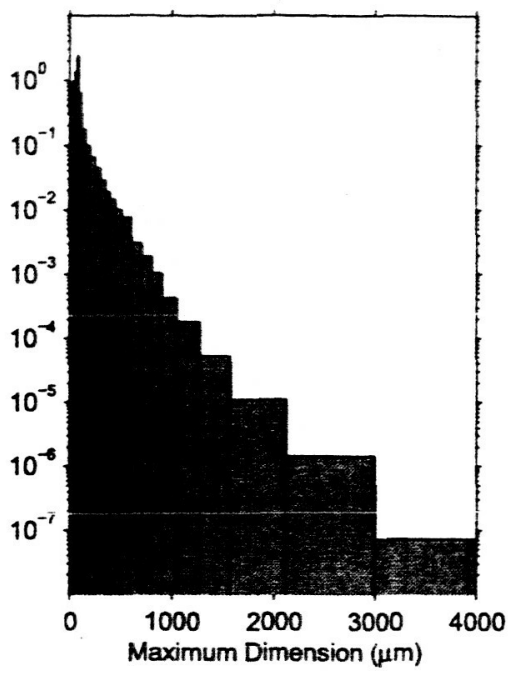

FIG. 2. Size distributions based on 27 size bins for the (a) FIRE-I, (b) FIRE-II, and (c) ARM cirrus microphysical models described in section 3 .

more complex cirrus scattering models that include more realistic particle size and habit distributions. In this study our intent is to form a new set of cirrus models based upon the particle size distribution and habit distribution observed by in situ measurements of cirrus. Previous studies involving in situ cirrus measurements have tended to focus on variability in the horizontal, whereas we wish to emphasize the vertical variability. The new cirrus models represent a significant improvement in the treatment of both the size distribution and the percentages of particle habits. The new cirrus models are based on 27 size bins, whereas the initial set of models was based on five size bins. The percentage of crystal habits for each size bin is based on reanalyses of in situ measurements from visual examination of slide collections (FIRE-I), balloonborne replicator data (FIRE-II), or CPI data (ARM).

Section 2 presents the data and models used in our analyses. Section 3 outlines the development of the new cirrus models. Results of RT calculations of top-of-atmosphere reflectances and brightness temperature differences are presented in section 4 . Section 5 summarizes and concludes our study.

\section{Data and models}

\section{a. Balloonborne replicator data: FIRE-II distributions}

The FIRE-II size distributions were measured on 25 and 26 November and 5 December 1991 by the National Center for Atmospheric Research (NCAR) balloonborne Formvar replicator (Miloshevich and Heymsfield 1997). Cloud characteristics for each of the FIRE-II cases are listed in Table 1. The size distribution data are discretized into 27 size regions ranging from $10 \mu \mathrm{m}$ to the largest measured size of $540 \mu \mathrm{m}$ at approximately 100 $m$ vertical layers through the cloud, with a visual classification of the two dominant crystal habits at each level. Images of vertical crystal profiles apparently show the presence of three vertical layers (Heymsfield and Miloshevich 1995): a production layer composed mostly of pristine crystals such as columns or plates, a growth layer, and a sublimation layer composed of large and often aggregated crystals.

An average number of particles per size bin is determined by integration over the height of each cloud layer as follows:

$$
\bar{n}(D)=\frac{\sum_{l=\text { cloud wop }}^{\text {cloud base }} n(D, l) \Delta z(l)}{\sum_{l=\text { cloud top }}^{\text {cloud base }} \Delta z(l)},
$$

where $l$ is a layer, $\Delta z(l)$ is the thickness of layer $l$, and $D$ is the center maximum dimension of the size bin. To determine the layer-averaged percentage of habit $h$ at size $D$, the habit information is averaged over height:

$$
f(h, D)=\frac{\sum_{l=\text { cloud top }}^{\text {cloud base }} f(h, D, l) n(D, l) \Delta z(l)}{\sum_{l=\text { cloud top }}^{\text {cloud base }} n(D, l) \Delta z(l)},
$$

where $f(h, D, l)$ is the percentage of habit $h$ at size $D$ and layer $l$.

\section{b. Aircraft data}

\section{1) FIRE-I DISTRIBUTIONS}

The FIRE-I data were collected from the NCAR King Air turboprop in October and November of 1986 over 
a)

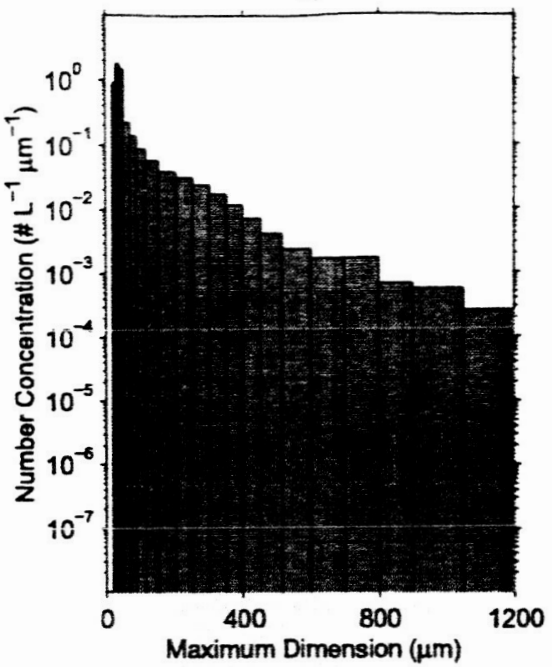

b)

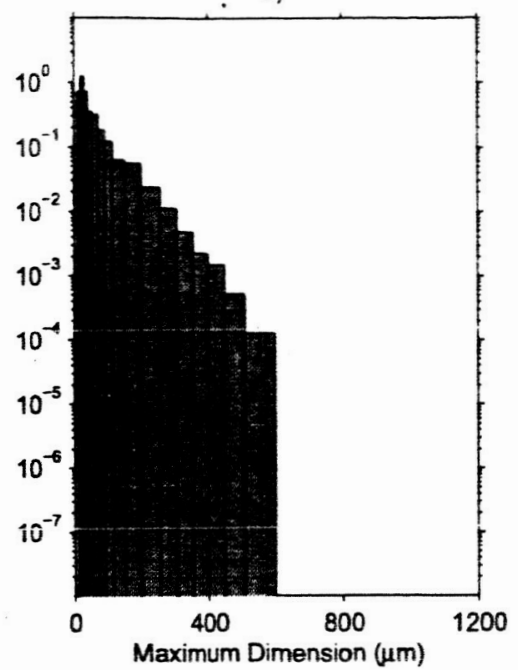

c)

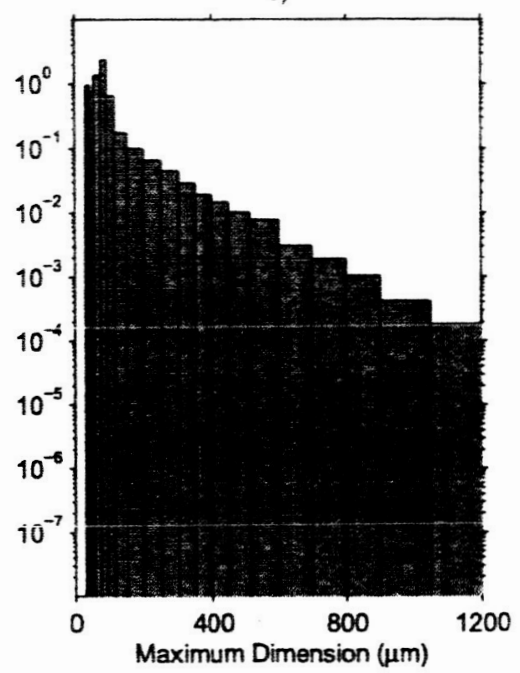

Fig. 3. As in Fig. 2, but the maximum crystal size is limited to $1200 \mu \mathrm{m}$ so that more detail is presented for the small-crystal size range.

Wisconsin. Ice particle size spectra were derived from Particle Measuring Systems, Inc., 2D-C and 2D-P imaging probe data. The 2D-C and 2D-P probes on the King Air measured particle size in $25-$ and $100-\mu \mathrm{m}$ intervals, respectively. A careful examination of slide collections provided information on the ice-particle habit percentages and the presence of small particles. In general, few small particles were noted in the collections. The data from the FSSP probe $(2-30 \mu \mathrm{m})$ were examined to see whether there were any pockets of liquid water or whether anomalously high concentrations (more than a few tenths per cubic centimeter) were present, which might suggest the presence of relatively high concentrations of ice particles. No such high concentrations were detected, suggesting that relatively low concentrations of total (and sub-2D-C size) particles were present. We have not attempted to account for the potential underrepresentation of small particles in the 2D-C data.

Cirrus cloud measurements on 22,25 , and 28 October, and 1-2 November of 1986 are used in this study. The aircraft climbed to cloud top in each case and then conducted a slow, Lagrangian-type spiral descent downward to cloud base. All FIRE-I data used were collected during the Lagrangian spiral descents. Cloud characteristics for each of the FIRE-I cases are listed in Table 1. The merged number concentration datasets use the 2D-C probe data for particle sizes between 25 and 600 $\mu \mathrm{m}$ and the 2D-P probe for $600-4000 \mu \mathrm{m}$. The number concentrations and habit distributions throughout the cloud are merged to create an averaged single-layer cloud model size distribution by

$$
\bar{n}(D)=\frac{\sum_{j=\text { cioud lop }}^{\text {clous base }} n(D, j)}{N_{\text {obs }}}
$$

and habit distribution

$$
f(h, D)=\frac{\sum_{j=\text { clous top }}^{\text {cloud base }} f(h, D, j)}{N_{\text {obs }}},
$$

respectively, where $N_{\text {obs }}$ is the number of observations and $j$ represents a single flight track through the cloud layer.

\section{2) ARM IOP DISTRIBUTIONS}

The ARM data were collected on 9 and 13 March 2000 by the University of North Dakota Citation aircraft near the ARM Cloud and Radiation Test Bed site in Oklahoma. Cloud characteristics are listed in Table 1. The data from 9 March are of a Lagrangian spiral, and those of $13 \mathrm{March}$ are for the entire flight. Ice-particle size spectra were derived from $2 \mathrm{D}-\mathrm{C}$ and $2 \mathrm{D}-\mathrm{P}$ probe data. The merged number concentration dataset uses the

\begin{tabular}{|c|c|c|c|c|c|c|}
\hline \multirow[b]{2}{*}{ Field campaign } & \multicolumn{2}{|c|}{5 size-bin fixed habit distribution } & \multicolumn{2}{|c|}{27 size-bin fixed habit distribution } & \multicolumn{2}{|c|}{27 size-bin measured habit distribution } \\
\hline & $\langle D\rangle(\mu \mathrm{m})$ & $D_{e}(\mu \mathrm{m})$ & $\langle D\rangle(\mu \mathrm{m})$ & $D_{e}(\mu \mathrm{m})$ & $\langle D\rangle(\mu \mathrm{m})$ & $D_{,}(\mu \mathrm{m})$ \\
\hline FIRE-I & 84.9 & 103.1 & 79.3 & 124.2 & 79.3 & 138.2 \\
\hline FIRE-II & 73.2 & 65.8 & 63.3 & 55.9 & 63.3 & 56.5 \\
\hline$A R M$ & 125.2 & 87.5 & 101.2 & 84.6 & 1012 & 61.0 \\
\hline
\end{tabular}

TABLE 4. Average maximum dimension and effective diameter based on the microphysical models described in section 3 
TARLE 5. Particle number distributions for 27 size bius.

\begin{tabular}{|c|c|c|c|c|}
\hline \multirow{2}{*}{$\underset{\substack{\text { Max } \\
\text { dimension }}}{ }$} & \multirow{2}{*}{$\begin{array}{l}\text { Bin- } \\
\text { width } \\
(\mu \mathrm{m})\end{array}$} & \multicolumn{3}{|c|}{ Number concentration $\left(\mathrm{L}^{-1} \mu \mathrm{m}^{-1}\right)$} \\
\hline & & FIRE-I & FIRE-II & ARM \\
\hline 3.0 & 4.5 & $0.0000 \times 10^{\circ}$ & $0.0000 \times 10^{0}$ & $0.0000 \times 10^{\circ}$ \\
\hline 7.5 & 6.0 & $0.0000 \times 10^{\circ}$ & $0.0000 \times 10^{0}$ & $0.0000 \times 10^{\circ}$ \\
\hline 15.0 & 8.75 & $0.0000 \times 10^{\circ}$ & $7.1873 \times 10^{-1}$ & $0.0000 \times 10^{\circ}$ \\
\hline 25.0 & 10.0 & $8.9809 \times 10^{-1}$ & $1.2310 \times 10^{\circ}$ & $0.0000 \times 10^{\circ}$ \\
\hline 35.0 & 10.0 & $1.7962 \times 10^{0}$ & $7.0759 \times 10^{-1}$ & $9.6154 \times 10^{-1}$ \\
\hline 45.0 & 12.5 & $1.4813 \times 10^{\circ}$ & $3.5406 \times 10^{-1}$ & $7.6923 \times 10^{-1}$ \\
\hline 60.0 & 17.5 & $2.2162 \times 10^{-1}$ & $3.1284 \times 10^{-1}$ & $1.3679 \times 10^{\circ}$ \\
\hline 80.0 & 20.0 & $1.3541 \times 10^{-1}$ & $1.7818 \times 10^{-1}$ & $2.3871 \times 10^{\circ}$ \\
\hline 100.0 & 25.0 & $8.6352 \times 10^{-2}$ & $1.1981 \times 10^{-1}$ & $6.5310 \times 10^{-1}$ \\
\hline 130.0 & 37.5 & $5.5901 \times 10^{-2}$ & $6.3147 \times 10^{-2}$ & $1.7268 \times 10^{-1}$ \\
\hline 175.0 & 47.5 & $3.7979 \times 10^{-2}$ & $5.4743 \times 10^{-2}$ & $9.9477 \times 10^{-2}$ \\
\hline 225.0 & 50.0 & $3.0645 \times 10^{-2}$ & $2.3840 \times 10^{-2}$ & $6.5906 \times 10^{-2}$ \\
\hline 275.0 & 50.0 & $2.4200 \times 10^{-2}$ & $1.1160 \times 10^{-2}$ & $4.4610 \times 10^{-2}$ \\
\hline 325.0 & 50.0 & $1.7150 \times 10^{-2}$ & $4.8503 \times 10^{-3}$ & $2.8637 \times 10^{-2}$ \\
\hline 375.0 & 50.0 & $1.1570 \times 10^{-2}$ & $2.2416 \times 10^{-3}$ & $1.9224 \times 10^{-2}$ \\
\hline 425.0 & 50.0 & $7.2273 \times 10^{-3}$ & $1.5066 \times 10^{-3}$ & $1.4565 \times 10^{-2}$ \\
\hline 475.0 & 62.5 & $4.2350 \times 10^{-3}$ & $5.2346 \times 10^{-4}$ & $1.0156 \times 10^{-2}$ \\
\hline 550.0 & 87.5 & $2.4228 \times 10^{-3}$ & $1.2870 \times 10^{-4}$ & $7.7074 \times 10^{-3}$ \\
\hline 650.0 & 100.0 & $1.7228 \times 10^{-3}$ & $0.0000 \times 10^{0}$ & $3.0205 \times 10^{-3}$ \\
\hline 750.0 & 100.0 & $1.7228 \times 10^{-3}$ & $0.0000 \times 10^{0}$ & $1.8922 \times 10^{-3}$ \\
\hline 850.0 & 100.0 & $6.9919 \times 10^{-4}$ & $0.0000 \times 10^{0}$ & $1.0486 \times 10^{-3}$ \\
\hline 950.0 & 150.0 & $5.7010 \times 10^{-4}$ & $0.0000 \times 10^{\circ}$ & $4.2422 \times 10^{-4}$ \\
\hline 1150.0 & 225.0 & $2.6070 \times 10^{-4}$ & $0.0000 \times 10^{\circ}$ & $1.8272 \times 10^{-4}$ \\
\hline 1400.0 & 300.0 & $1.1388 \times 10^{-4}$ & $0.0000 \times 10^{\circ}$ & $5.3236 \times 10^{-5}$ \\
\hline 1750.0 & 550.0 & $3.4327 \times 10^{-5}$ & $0.0000 \times 10^{0}$ & $1.0878 \times 10^{-5}$ \\
\hline 2500.0 & 875.0 & $5.3546 \times 10^{-6}$ & $0.0000 \times 10^{0}$ & $1.4242 \times 10^{-6}$ \\
\hline 3500.01 & 1000.0 & $2.2661 \times 10^{-7}$ & $0.0000 \times 10^{0}$ & $7.2145 \times 10^{-8}$ \\
\hline
\end{tabular}

2D-C probe data for particle sizes between 25 and 900 $\mu \mathrm{m}$ and the 2D-P probe data for $900-4000 \mu \mathrm{m}$. We have not accounted for the potential underrepresentation of small crystals in the 2D-C data. Averaged singlelayer cloud model size distributions are determined from Eq. (4). Particle habit distributions were derived from visual examination of SPEC, Inc., CPI data. Virtually all of the particles were bullet rosettes with an average of five bullets per rosette. Larger particles were aggregates of rosettes.

\section{c. Single-scattering properties}

An extensive library of single-scattering properties has been prepared that encompasses five randomly oriented crystal habits, 27 size bins, and 10 subbands within each of the MODIS band numbers in Table 2. The crystal habits are solid hexagonal columns, hexagonal plates, hollow hexagonal columns, two-dimensional bullet rosettes, and moderately rough aggregated columns. Because the columnar crystals in the King Air slide collections and in the replicator data are hollow, all columnar crystals are treated as being hollow columns. The size bins span a maximum dimension range of 3-3500 $\mu \mathrm{m}$.

The single-scattering calculations are derived using a combination of the improved geometric optics method (GOM2) and the finite-difference time domain (FDTD) techniques discussed in Yang and Liou $(1996 a, b)$. The
TABle ó. Fixed and measured habit distributions. All particle sizes $D$ are in micrometers.

\begin{tabular}{lcccc}
\hline \hline & $\begin{array}{c}\text { Fixed } \\
\text { percentages }\end{array}$ & FIRE-I & FIRE-II & ARM \\
\cline { 2 - 5 } & $D<70$ & $D<150$ & $D<100$ & $D<100$ \\
First size limit & $\mu \mathrm{m}$ & $\mu \mathrm{m}$ & $\mu \mathrm{m}$ & $\mu \mathrm{m}$ \\
\hline Bullet rosettes & $50 \%$ & $37 \%$ & $35 \%$ & $0 \%$ \\
Hexagonal plates & $25 \%$ & $0 \%$ & $46 \%$ & $75 \%$ \\
Hollow columns & $25 \%$ & $63 \%$ & $17 \%$ & $6 \%$ \\
Aggregates & $0 \%$ & $0 \%$ & $3 \%$ & $19 \%$ \\
& & & & $100 \mu \mathrm{m}<$ \\
& $D>70$ & $D>150$ & $D>100$ & $D<800$ \\
Second size limit & $\mu \mathrm{m}$ & $\mu \mathrm{m}$ & $\mu \mathrm{m}$ & $\mu \mathrm{m}$ \\
\hline Bullet rosettes & $30 \%$ & $33 \%$ & $38 \%$ & $100 \%$ \\
Hexagonal plates & $20 \%$ & $0 \%$ & $0 \%$ & $0 \%$ \\
Hollow columns & $20 \%$ & $27 \%$ & $22 \%$ & $0 \%$ \\
Aggregates & $30 \%$ & $40 \%$ & $40 \%$ & $0 \%$ \\
& & & & $D>800$ \\
Third size limit & & & & $\mu \mathrm{m}$ \\
\hline Bullet rosettes & $0 \%$ & $0 \%$ & $0 \%$ & $75 \%$ \\
Hexagonal plates & $0 \%$ & $0 \%$ & $0 \%$ & $0 \%$ \\
Hollow columns & $0 \%$ & $0 \%$ & $0 \%$ & $0 \%$ \\
Aggregates & $0 \%$ & $0 \%$ & $0 \%$ & $25 \%$ \\
\hline
\end{tabular}

FDTD is applied to particles having a size parameter smaller than 20, whereas GOM2 is employed for size parameters larger than 20. Calculated properties include the extinction coefficient, single-scattering albedo, fraction of delta-transmitted energy, asymmetry parameter, and scattering phase function.

\section{d. Atmospheric absorption}

For this study, we have focused our attention upon the creation of correlated $k$-distribution routines for the spectral regions corresponding to the MODIS channels. Because these correlated $k$-distribution routines have been formulated specifically for the MODIS channels rather than being adapted from other studies, we can be assured that the routines correctly represent the observed radiative impact due to molecular absorption within these spectral bands. Although our correlated $k$ distribution routines could be applied to an assessment of the state of the molecular inventory within the atmosphere, we have used these routines to remove the - molecular signal from the data, thereby allowing for an analysis of the radiative impacts of other aerosols, clouds, surface conditions, and so on.

A major advantage of using the correlated $k$-distribution method is that it can be incorporated directly into multiple scattering routines used to consider scattering as well as absorption by clouds and aerosol particles (Lacis and Oinas 1991). Kratz (1995) provides an in-depth description of the method used to create the correlated $k$-distribution routines. For both that study and our investigation, the derivation of the correlated $k$ distributions has been based upon an exponential sum fitting of transmissions technique (Wis- 
TABLE 7. Single-scattering albedos $\omega_{0}$ for a set of MODIS wavelengths derived for the cirsus micioplysicai models described in section 3 .

\begin{tabular}{|c|c|c|c|c|c|c|c|c|c|}
\hline \multirow[b]{2}{*}{$\lambda(\mu \mathrm{m})$} & \multicolumn{3}{|c|}{ FIRE-I } & \multicolumn{3}{|c|}{ FIRE-II } & \multicolumn{3}{|c|}{ ARM } \\
\hline & $\begin{array}{l}5 \text { size-bins } \\
\text { fixed habit }\end{array}$ & $\begin{array}{l}27 \text { size-bins } \\
\text { fixed habit }\end{array}$ & $\begin{array}{c}27 \text { size-bins } \\
\text { measured } \\
\text { habit }\end{array}$ & $\begin{array}{l}5 \text { size-bins } \\
\text { fixed habit }\end{array}$ & $\begin{array}{l}27 \text { size-bins } \\
\text { fixed habit }\end{array}$ & $\begin{array}{c}27 \text { size-bins } \\
\text { measured } \\
\text { habit }\end{array}$ & $\begin{array}{l}5 \text { size-bins } \\
\text { fixed habit }\end{array}$ & $\begin{array}{l}27 \text { size-bins } \\
\text { fixed habit }\end{array}$ & $\begin{array}{c}27 \text { size-bins } \\
\text { measured } \\
\text { habit }\end{array}$ \\
\hline 0.65 & 1.000 & 1.000 & 1.000 & 1.000 & 1.000 & 1.000 & 1.000 & 1.000 & 1.000 \\
\hline 1.38 & 0.9919 & 0.9904 & 0.9889 & 0.9947 & 0.9955 & 0.9953 & 0.9930 & 0.9933 & 0.9951 \\
\hline 1.64 & 0.9063 & 0.8834 & 0.8835 & 0.9334 & 0.9418 & 0.9406 & 0.9182 & 0.9214 & 0.9399 \\
\hline 2.13 & 0.8555 & 0.8434 & 0.8244 & 0.8912 & 0.9016 & 0.8999 & 0.8698 & 0.8735 & 0.8957 \\
\hline 3.78 & 0.6513 & 0.6486 & 0.6262 & 0.6834 & 0.7062 & 0.6995 & 0.6632 & 0.6777 & 0.7113 \\
\hline 8.52 & 0.5803 & 0.5775 & 0.5677 & 0.5919 & 0.6127 & 0.6227 & 0.5828 & 0.6015 & 0.6271 \\
\hline 11.0 & 0.5397 & 0.5400 & 0.5369 & 0.5340 & 0.5284 & 0.5280 & 0.5389 & 0.5357 & 0.5356 \\
\hline 12.0 & 0.5680 & 0.5682 & 0.5648 & 0.5653 & 0.5635 & 0.5641 & 0.5677 & 0.5671 & 0.5694 \\
\hline
\end{tabular}

combe and Evans 1977) that was applied to the results of line-by-line calculations that were run at predetermined reference pressure and temperature conditions. Both studies have relied upon the multiplication transmissivity property to account for the overlap of the spectral features associated with the various molecular species. We have established the accuracy of the correlated $k$ distribution technique, as compared with the line-by-line method, by running atmospheric flux and heating rate calculations for a wide variety of atmospheric conditions.

\section{e. Radiative transfer model}

Baum et al. (2000) describe the use of a discrete ordinates radiative transfer model to calculate the topof-atmosphere (TOA) radiances expected for a range of clear and cloudy conditions for the wavelengths listed in Table 2. The atmosphere is composed of a discrete number of adjacent homogeneous layers. Within each layer, the single-scattering albedo and optical thickness are constant, but these values may vary from layer to layer. For the 1.64-, 1.38-, 2.13-, 3.78-, 8.5-, 11-, and $12-\mu \mathrm{m}$ channels, the atmosphere is divided into 34 layers between the surface and $70 \mathrm{~km}$. For each layer, the correlated $k$-distribution routines discussed in the previous section are implemented to calculate optical thicknesses due to gaseous absorption. For the $0.65-\mu \mathrm{m}$ channel, for which ozone is the principal absorber and Rayleigh scattering is important, the atmosphere is modeled with four layers. The first (uppermost) layer includes the effect of ozone absorption and Rayleigh scattering from the tropopause to the TOA. The second layer includes Rayleigh scattering between the top of the uppermost cloud and the tropopause. The third layer contains the optical properties for either a water or an icephase cloud. The layer below the cloud contains Rayleigh scatterers. Aerosol contributions are neglected in this study.

\section{Development of cirrus models}

a. Cirrus microphysical models

In the MODIS version-1 cirrus models described by Baum et al. (2000), the habit distribution is the same for all of the models but the number concentration of ice crystals per size bin varies between the models. The data upon which we base this study were collected during the FIRE-I (1986), FIRE-II (1991), and ARM IOP (2000) field campaigns. As discussed in section 2, the data are culled from five cirrus flight missions during FIRE-I, three flight missions during FIRE-II, and two flight missions during the ARM IOP.

Two values used to describe a given particle size distribution are the average maximum dimension and the effective diameter. The average maximum dimension of a distribution $\langle D\rangle$ is defined as

$$
\langle D\rangle=\frac{\sum_{D=D_{\min }}^{D_{\max }} D n(D) \Delta(D)}{\sum_{D=D_{\operatorname{mix}}}^{D_{\max }} n(D) \Delta(D)},
$$

where $D_{\min }$ and $D_{\max }$ describe the minimum and maximum crystal sizes in the distribution, respectively, and $\Delta(D)$ is the width of size bin $D$. The average maximum dimension characterizes the bulk properties of the size distribution. The second value is the effective diameter $D_{e}$. Wyser and Yang (1998) demonstrated that the details of the size distribution are relatively unimportant in specifying the bulk optical properties of cirrus when the effective size is calculated as the total volume $V$ of the particles divided by the total projected area $A$. This definition is related directly to ice water content IWC because $V=I W C / \rho$, where $\rho$ is the density of ice. We define $D_{e}$ after Foot (1988) and Francis et al. (1994) as

$$
D_{e}=\frac{3}{2} \frac{\sum_{D=D_{\min }}^{D_{\max }}\left[\sum_{h=1}^{4} V(h, D) f(h, D) n(D) \Delta(D)\right]}{\sum_{D=D_{\min }}^{D_{\max }}\left[\sum_{h=1}^{4} A(h, D) f(h, D) n(D) \Delta(D)\right]},
$$

where $f(h, D)$ is the percentage of a specific particle habit for size $D$, and $n(D)$ is the number concentration of crystals.

To investigate the effects of habit distribution and number of size bins on the cirrus single-scattering prop- 

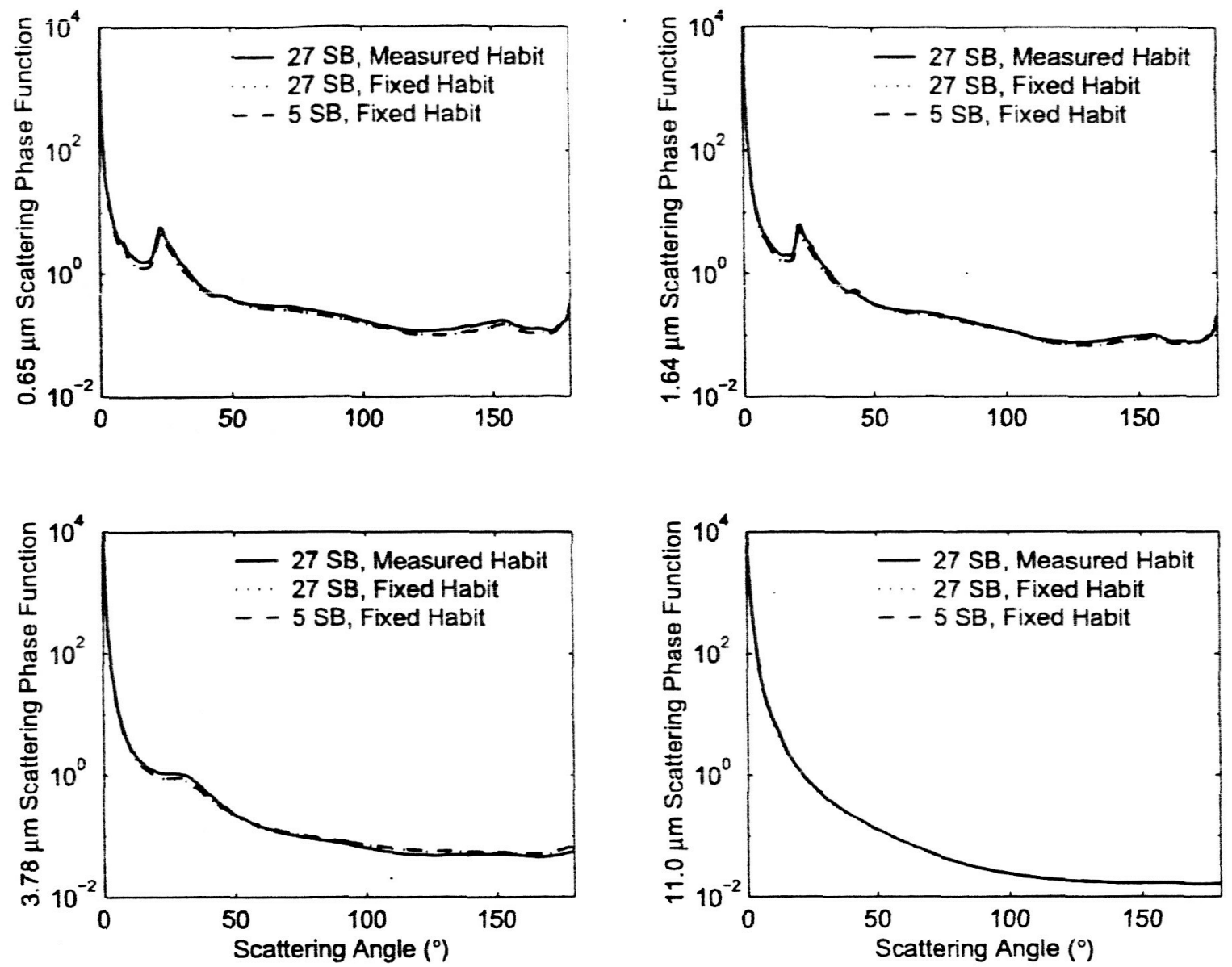

FIG. 4. Scattering phase functions based on FIRE-I data for the three cirrus microphysical models described in section 3 for four wavelengths: $0.65,1.64,3.78$, and $11.0 \mu \mathrm{m}$.

erties (SSP), we created three sets of cirrus models using the SSP library. The three model sets are as follows.

1) The cirrus models, based on FIRE and ARM in situ measurements, have five size bins and the MODIS version-1 fixed habit percentages (i.e., the same habit percentages are used for each model). The maximum dimension does not exceed $1100 \mu \mathrm{m}$.

2) The cirrus models have expanded size distributions ( 27 size bins) based on in situ data but have the MODIS version-1 fixed habit distribution.

3) The cirrus models have expanded size distributions containing 27 size bins and habit distributions based on in situ data.

These models will now be discussed in detail.

\section{1) CiRrus MOdels: Five SIZE BINS AND FIXED HABIT DISTRIBUTION}

As. a first step in developing cirrus models from in situ data, the first set of models is patterned after those presented in Baum et al. (2000). The flight-track-av- eraged size distributions are discretized into five size bins as shown in Fig. 1 and tabulated in Table 3. As with the Baum et al. (2000) models, however, the habit distributions for each bin are kept constant for each model. When the maximum dimension $D$ is small ( $D$ $<70 \mu \mathrm{m}$ ), that is, for the smallest two size bins, the percentage of ice crystals within the size region is assumed to be $50 \%$ bullet rosettes, $25 \%$ hexagonal plates, and $25 \%$ hollow hexagonal columns. When $D$ is greater than $70 \mu \mathrm{m}$ (i.e., for the largest three size bins), the percentage of ice crystals within the size region is $30 \%$ aggregates, $30 \%$ bullet rosettes, $20 \%$ hexagonal plates, and $20 \%$ hollow hexagonal columns. The $D_{e}$ and $\langle D\rangle$ values for these distributions are listed in Table 4.

\section{2) CirRus Models: TWENTY-SEVEN SIZE BINS AND FIXED HABIT PERCENTAGES}

In this section, the in situ data used in the previous section are discretized into 27 size bins while the habit distribution is left unchanged. The 27 size bins cover a 

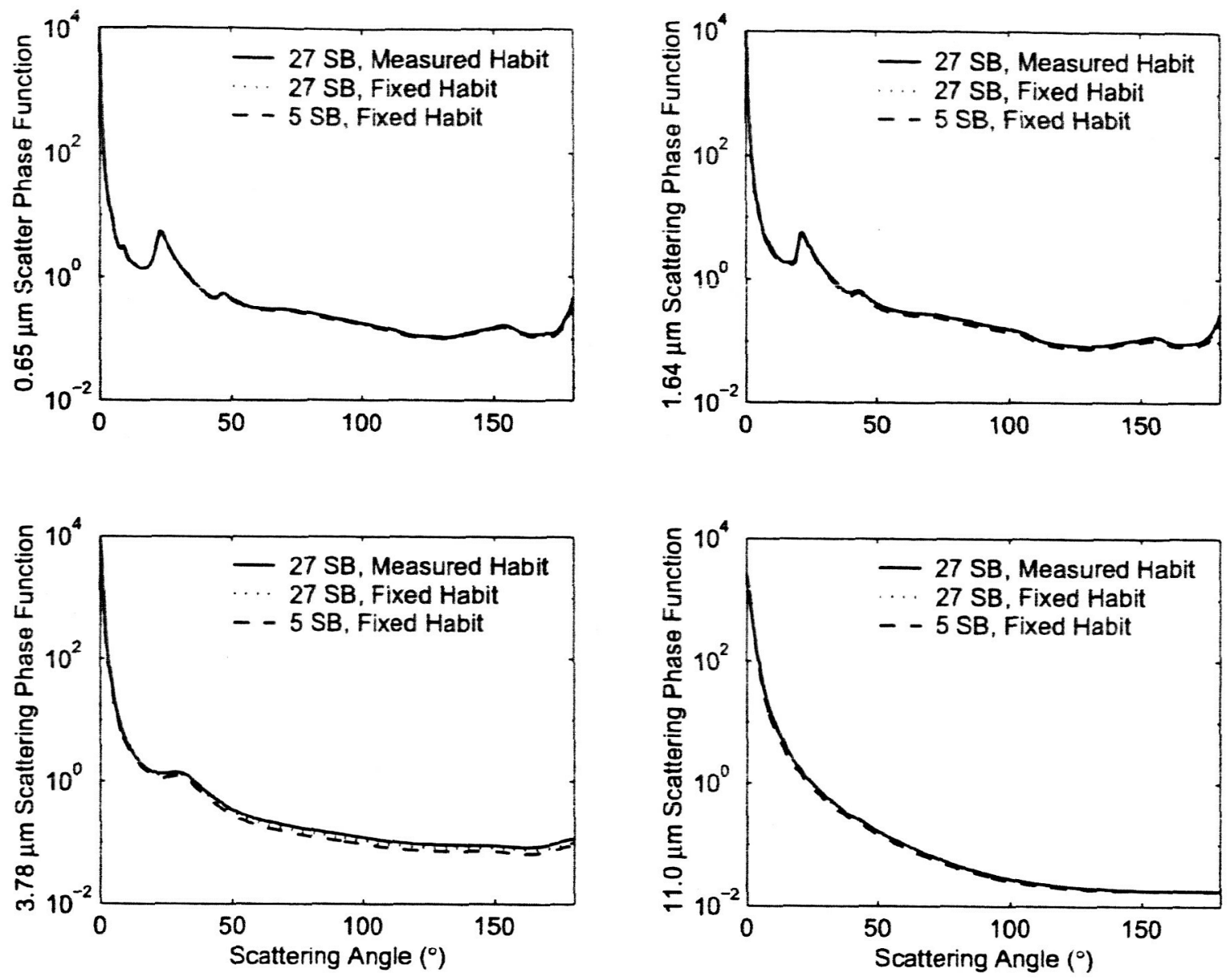

Fig. 5. Same as Fig. 4 but based on FIRE-II data.

size range from 3 to $3500 \mu \mathrm{m}$. The average number concentration $n(D)$ for each size bin is determined by

$$
n(D)=\frac{\sum_{\text {case }=1}^{N} n(D, \text { case }) \Delta(D)}{\sum_{\text {case }=1}^{N} \Delta(D)},
$$

where $N$ refers to the number of individual cirrus cases. For FIRE-I and ARM, the in situ measurements were obtained by aircraft, but balloon replicators were used in FIRE-II. Where aircraft were used, a case would represent the data collected for all the flight tracks for a cirrus mission on any given day. When replicators were used, a case would be an entire dataset collected for the path taken through the cirrus.

Figure 2 shows the size distributions calculated from averages of five cases from FIRE-I, three cases from FIRE-II, and two cases from ARM. Figure 3 shows the same size distributions as in Fig. 2, but the size range is limited to $1200 \mu \mathrm{m}$ to bring out the detail of the small size bins. Note that there are no large particles recorded by the replicator data as there are from the aircraft probe measurements. Table 5 provides the number concentrations for the size distributions. Based on an average of the five cases from FIRE-1, the sizes range from 25 to $3500 \mu \mathrm{m}$. The particle sizes for the FIRE-II replicator data range from 15 to $600 \mu \mathrm{m}$, and the sizes from the two ARM IOP cases range from 35 to $3500 \mu \mathrm{m}$. Table 4 provides average values of $\langle D\rangle$ and $D_{e}$ for these cases.

3) CiRRus MOdels: TWENTY-SEVEN SIZE BINS AND MEASURED HABIT PERCENTAGES

At this point, the in situ data for the cirrus models have been discretized into 27 size bins. In this section, the in situ data are used to provide averages of habits based on particle size as follows. The average distribution habit weights $f(D)$ are determined by

$$
f(D)=\frac{\sum_{\text {case }=1}^{N} f(D, \text { case }) n(D, \text { case }) \Delta(D)}{\sum_{\text {case }=1}^{N} n(D, \text { case }) \Delta(D)},
$$

where $N$ refers to the total number of cases. 

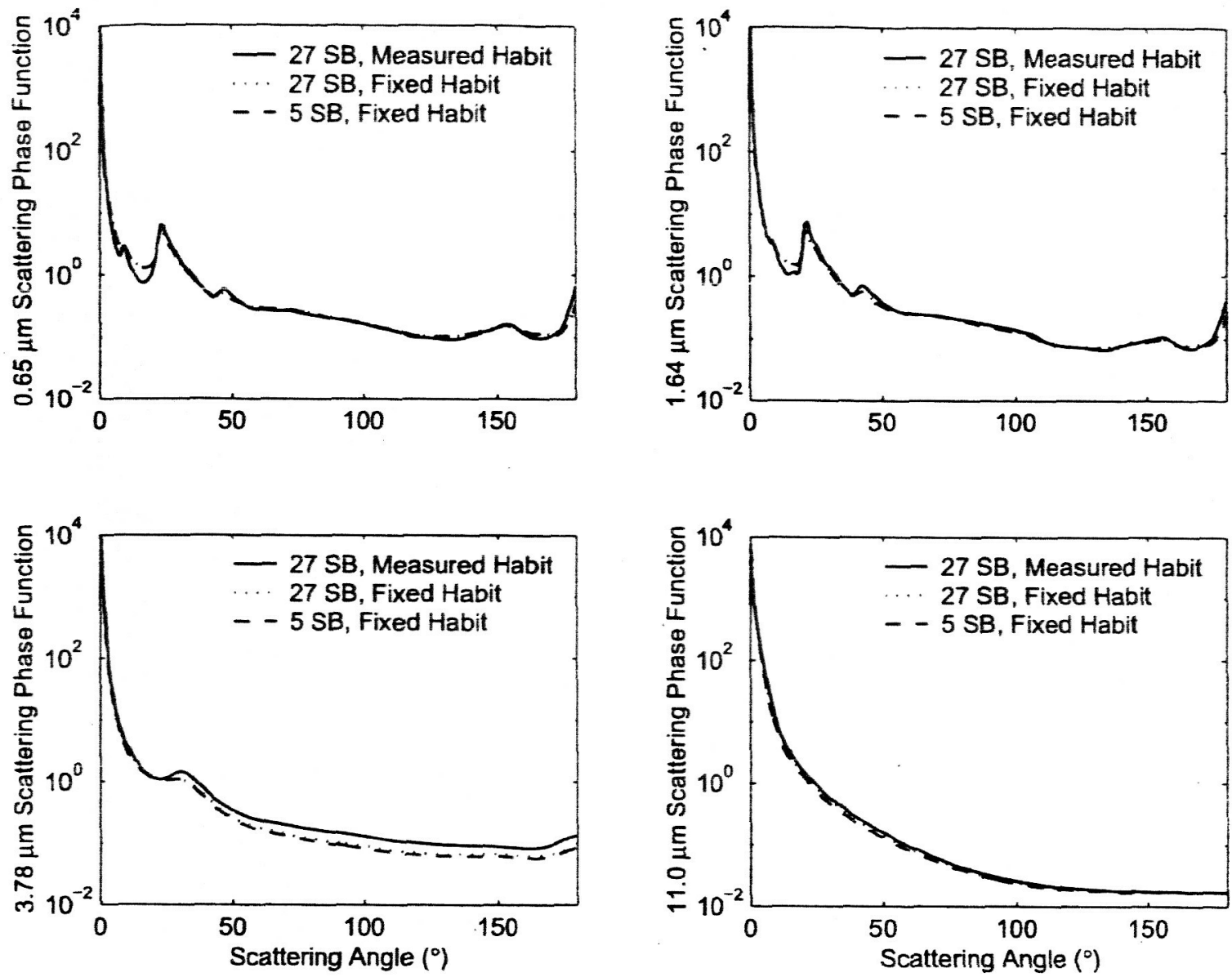

Fig. 6. Same as Fig. 4 but based on ARM data.

The averaged habit distributions based on the in situ measurements is provided in Table 6 . We note that although aggregated crystals are found in situ only for crystal sizes greater than about $300 \mu \mathrm{m}$, we include them in our models at smaller sizes to account for particles that have complex or rough shapes, even though the observed crystals may not technically have been aggregates. Table 4 shows the $\langle D\rangle$ and $D_{e}$ values calculated when both particle size and habit are incorporated into the calculations.

\section{4) COMPARISON OF MODEL EFFECTIVE DIAMETERS}

Comparison of $D_{e}$ values in Table 4 shows clearly the sensitivity of both size distribution and habit in the calculations. For the FIRE-I data, an increase from five size bins $(103.1 \mu \mathrm{m})$ to 27 size bins $(124.2 \mu \mathrm{m})$ results in an increase of $D_{e}$ by $20 \%$, whereas a further modification in the habit distribution results in an additional increase in $D$, of $11 \%$. Much of this difference probably can be attributed to the greater range of sizes in the 27 - bin case $(3-4000 \mu \mathrm{m})$ than in the five-bin case $(5-1070$ $\mu \mathrm{m})$. The largest crystals are not included in the fivesize bin distribution.

For the FIRE-II case, $D_{e}$ decreases by $18 \%$ when the number of size bins increases from 5 to 27 , keeping the habit distribution fixed. Furthermore, modifying the distribution of habits has little appreciable effect on $D_{e}$. For the ARM data, an increase the number of size bins has almost no effect on $D_{e}$, changing the value by only $1 \%$. However, for the ARM cirrus model, the $D_{e}$ shows a surprising sensitivity to particle shape. It is important to note that the ARM data are composed of measurements from cirrus uncinus that were composed primarily of bullet rosettes. Although the maximum dimension of a bullet rosette may be very large, the ratio of total volume to projected area is typically much smaller, resulting in a smaller value for $D_{c}$.

These results suggest that the retrieval of $D_{e}$ from satellite data will depend critically on the assumed distributions of both particle size and habit and point to the need for more in situ data. 


\section{b. Cirrus single-scattering properties}

A MODIS band-averaged size distribution is created by integrating single-scattering properties over the spectral response function (SRF), habit distribution, and size distribution. The SRF weights $f_{\lambda}$ are normalized with respect to the discrete spectral subbands sb such that

$$
\sum_{s b=1}^{10} f_{\lambda}(s b)=1 .
$$

The mean extinction and scattering cross sections are given by

$$
\begin{aligned}
& \bar{\sigma}_{\text {ext }}=\frac{\sum_{D=D_{\min }}^{D_{\max }}\left\{\sum_{h=1}^{4} f(h, D) n(D) \Delta(D)\left[\sum_{\mathrm{sb}} \sigma_{\mathrm{ext}}(h, D, \mathrm{sb}) f_{\lambda}(\mathrm{sb})\right]\right\}}{\sum_{D=D_{\max }}^{D_{\max }}\left[\sum_{h=1}^{4} f(h, D) n(D) \Delta(D)\right]} \text { and } \\
& \bar{\sigma}_{\mathrm{sca}}=\frac{\sum_{D=D_{\min }}^{D_{\max }}\left\{\sum_{h=1}^{4} f(h, D) n(D) \Delta(D)\left[\sum_{\mathrm{sb}} \sigma_{\mathrm{sca}}(h, D, \mathrm{sb}) f_{\lambda}(\mathrm{sb})\right]\right\}}{\sum_{D=D_{\operatorname{mix}}}^{D_{\max }}\left[\sum_{h=1}^{4} f(h, D) n(D) \Delta(D)\right]},
\end{aligned}
$$

respectively, where $h$ refers to the habit (summed over hexagonal plates, hollow columns, bullet rosettes, and aggregates), $f_{\lambda}$ refers to the SRF weights, and $\Delta(D)$ is the width of size bin $D$. The extinction coefficient is given by

$$
\begin{aligned}
\bar{\beta}_{\text {ext }}=\sum_{D=D_{\min }}^{D_{\max }}\left\{\sum_{h=1}^{4} f(h, D) n(D) \Delta(D)\right. \\
\left.\times\left[\sum_{\mathrm{st}} \sigma_{\mathrm{ext}}(h, D, \mathrm{sb}) f_{\lambda}(\mathrm{sb})\right]\right\} .
\end{aligned}
$$

The dimensionless optical thickness of the cloud may be obtained from this relationship:

$$
\tau=\beta_{\mathrm{ext}} \Delta z
$$

where $\Delta z$ is the cloud geometrical thickness.

The averaged single-scattering albedo, delta-transmitted energy, and phase function at scattering angle $\Theta$ are given, respectively, by

$$
\begin{aligned}
& \bar{\omega}_{o}= \frac{\bar{\sigma}_{\mathrm{sca}}}{\bar{\sigma}_{\mathrm{ext}}}, \\
& \bar{f}_{\delta}=\frac{\sum_{D=D_{\min }}^{D_{\max }}\left\{\sum_{h} f(h, D) n(D) \Delta(D)\left[\sum_{\mathrm{sb}} f_{\delta}(h, D, \mathrm{sb}) \sigma_{\mathrm{sca}}(h, D, \mathrm{sb}) f_{\lambda}(\mathrm{sb})\right]\right\}}{\sum_{D=D_{\min }}^{D_{\max }}\left\{\sum_{h} f(h, D) n(D) \Delta(D)\left[\sum_{\mathrm{sb}} \sigma_{\mathrm{sca}}(h, D, \mathrm{sb}) f_{\lambda}(\mathrm{sb})\right]\right\}} \text { and } \\
& \bar{P}(\Theta)=\frac{\sum_{D=D_{\operatorname{ma}}}^{D_{\max }}\left\{\sum_{h} f(h, D) n(D) \Delta(D)\left[\sum_{\mathrm{sb}} P(\Theta, h, D, \mathrm{sb}) \sigma_{\mathrm{sca}}(h, D, \mathrm{sb}) f_{\lambda}(\mathrm{sb})\right]\right\}}{\sum_{D=D_{\min }}^{D_{\max }}\left\{\sum_{\mathrm{hab}} f(h, D) n(D) \Delta(D)\left[\sum_{\mathrm{sb}} \sigma_{\mathrm{sca}}(h, D, \mathrm{sb}) f_{\lambda}(\mathrm{sb})\right]\right\}}
\end{aligned}
$$


TABLE 8. Extinction coefficients $\beta_{e}\left(\mathrm{~km}^{-1}\right)$ for a set of MODIS wavelengths derived for the cirrus microphysical models described in section 3 .

\begin{tabular}{|c|c|c|c|c|c|c|c|c|c|}
\hline \multirow[b]{2}{*}{$\lambda(\mu \mathrm{m})$} & \multicolumn{3}{|c|}{ FIRE-I } & \multicolumn{3}{|c|}{ FIRE-II } & \multicolumn{3}{|c|}{ ARM } \\
\hline & $\begin{array}{l}5 \text { size-bins } \\
\text { fixed habit }\end{array}$ & $\begin{array}{c}27 \text { size-bins } \\
\text { fixed habit }\end{array}$ & $\begin{array}{c}27 \text { size-bins } \\
\text { measured } \\
\text { habit }\end{array}$ & $\begin{array}{l}5 \text { size-bins } \\
\text { fixed babit }\end{array}$ & $\begin{array}{l}27 \text { size-bins } \\
\text { fixed habit }\end{array}$ & $\begin{array}{c}27 \text { size-bins } \\
\text { measured } \\
\text { habit }\end{array}$ & $\begin{array}{l}5 \text { size-bins } \\
\text { fixed habit }\end{array}$ & $\begin{array}{l}27 \text { size-bins } \\
\text { fixed habit }\end{array}$ & $\begin{array}{c}27 \text { size-bins } \\
\text { measured } \\
\text { habit }\end{array}$ \\
\hline 0.65 & 0.752 & 0.735 & 0.718 & 0.362 & 0.276 & 0.269 & 2.169 & 1.546 & 1.326 \\
\hline 1.38 & 0.759 & 0.738 & 0.716 & 0.362 & 0.276 & 0.267 & 2.168 & 1.551 & 1.333 \\
\hline 1.64 & 0.750 & 0.736 & 0.716 & 0.362 & 0.276 & 0.269 & 2.175 & 1.548 & 1.321 \\
\hline 2.13 & 0.765 & 0.739 & 0.719 & 0.369 & 0.276 & 0.270 & 2.196 & 1.545 & 1.303 \\
\hline 3.78 & 0.745 & 0.733 & 0.716 & 0.358 & 0.277 & 0.268 & 2.153 & 1.559 & 1.355 \\
\hline 8.52 & 0.757 & 0.738 & 0.714 & 0.357 & 0.277 & 0.278 & 2.169 & 1.590 & 1.404 \\
\hline 11.0 & 0.716 & 0.701 & 0.680 & 0.338 & 0.253 & 0.246 & 2.065 & 1.456 & 1.250 \\
\hline 12.0 & 0.739 & 0.723 & 0.701 & 0.353 & 0.268 & 0.261 & 2.132 & 1.516 & 1.310 \\
\hline
\end{tabular}

Table 7 provides the single-scattering albedos $\omega_{o}$ that have been computed for a set of MODIS wavelengths for the cirrus microphysical models developed in section 3. For all cirrus microphysical models, the value of $\omega_{0}$ is 1 at $0.65 \mu \mathrm{m}$, but that value tends to decrease with increasing wavelength. At the near-infrared (NIR) wavelength of $1.38 \mu \mathrm{m}$, the calculations show that $\omega_{o}$ does not depend very strongly on either the discretization of the size distribution or variations in the crystal habit distributions.

At NIR wavelengths of $1.64,2.13$, and $3.78 \mu \mathrm{m}$, where the imaginary index of refraction for ice has a much higher value than at 0.65 or $1.38 \mu \mathrm{m}$, the $\omega_{o}$ values are shown to have more dependence on the details of
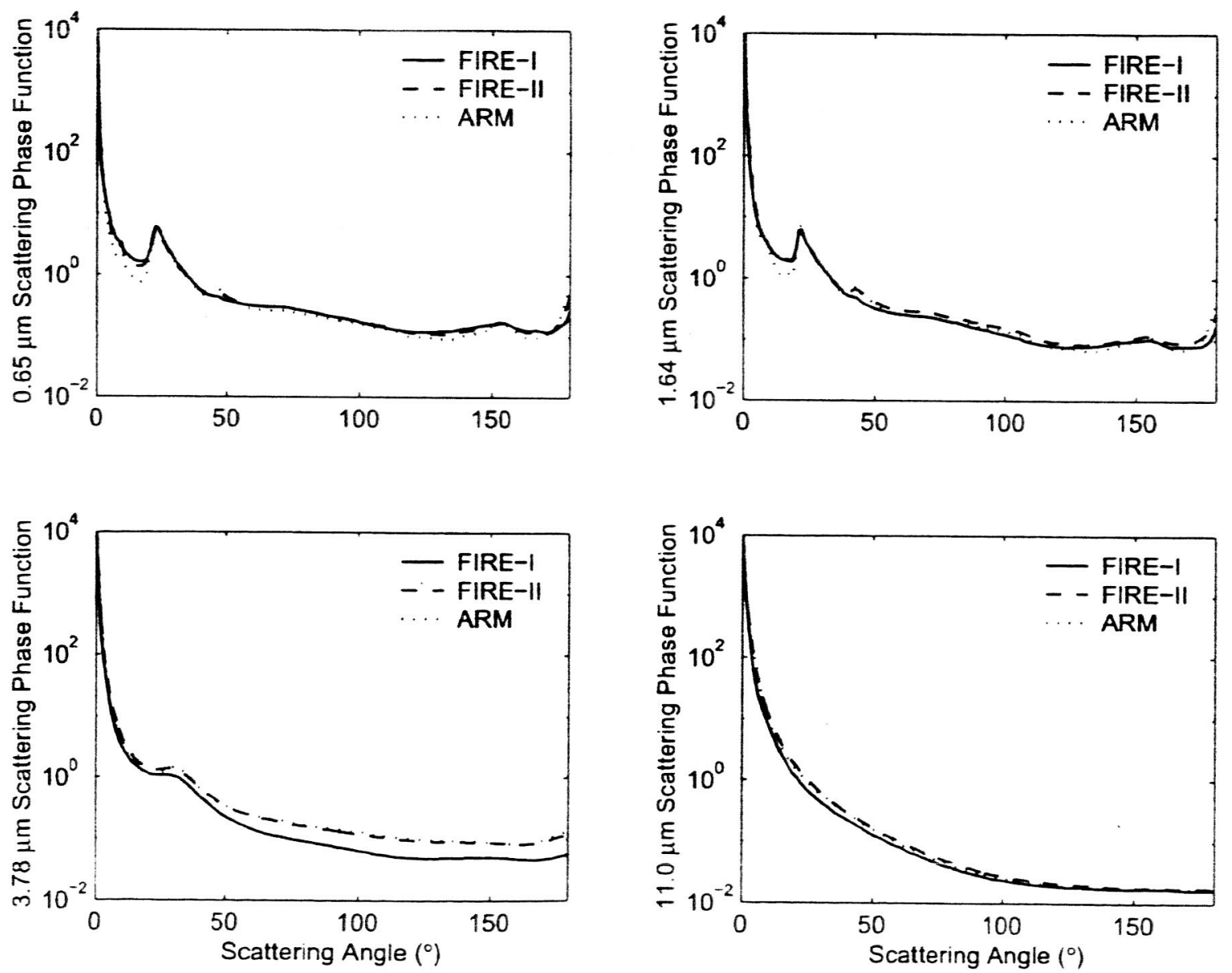

FiG. 7. Scattering phase functions for FIRE-I, FIRE-II, and ARM data for the cirrus microphysical models described in section $3 \mathrm{c}$ (27 size bins, measured habit distributions) for four wavelengths: $0.65,1.64,3.78$, and $11.0 \mu \mathrm{m}$. 
a)

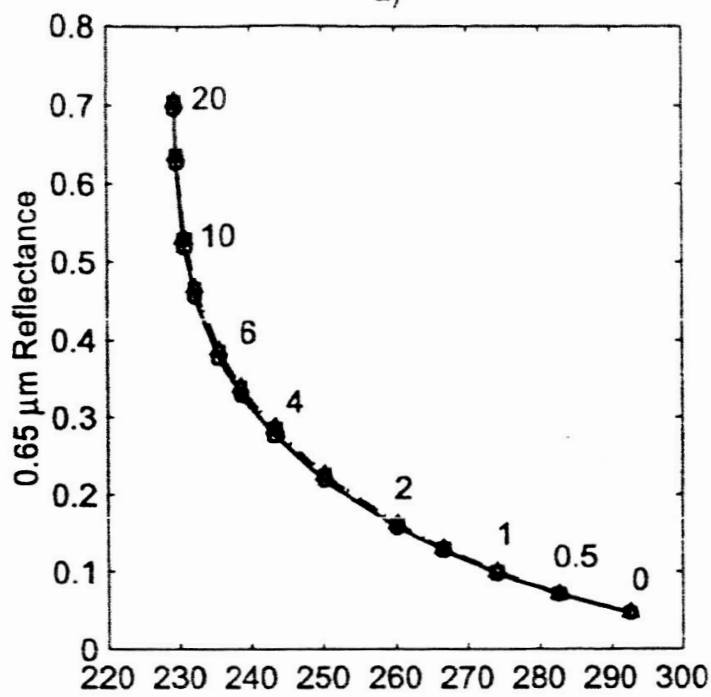

c)

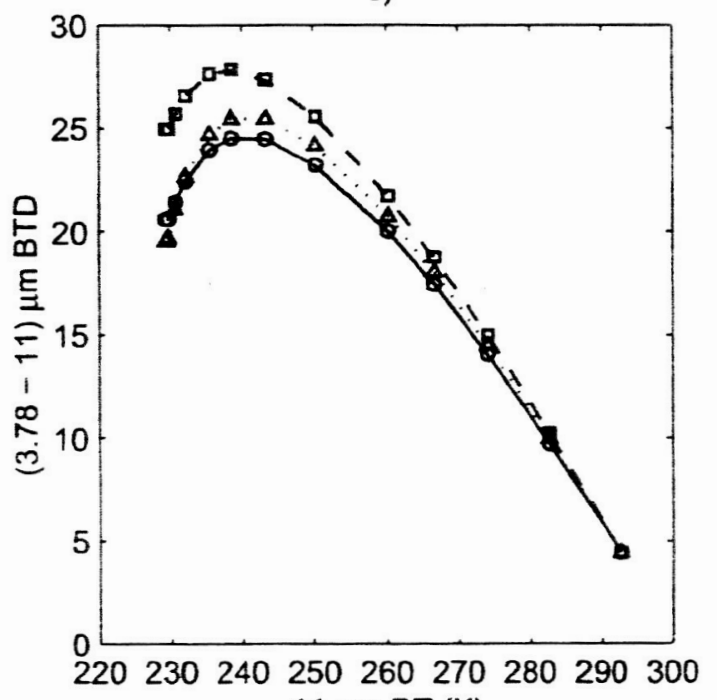

b)

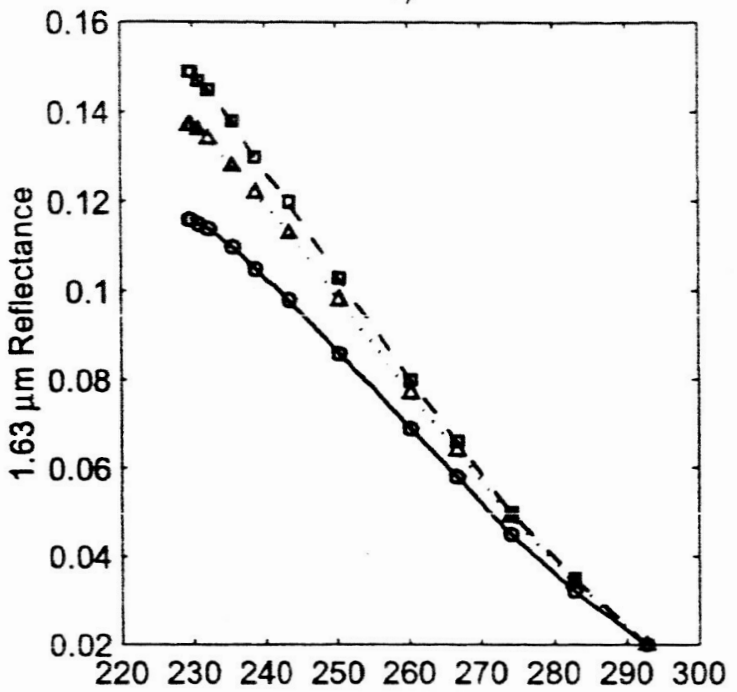

d)

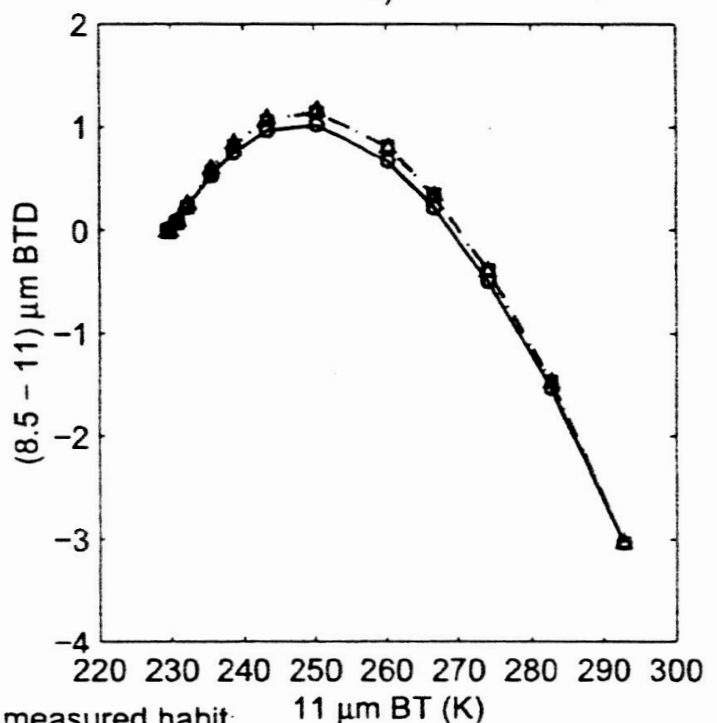

$\triangle 27$ size bins, fixed habit

$\rightarrow-5$ size bins, fixed habit

FIG. 8. Radiative transfer results generated using the FIRE-I cirms microphysical models derived in section 3 for (a) 0.65 - $\mu \mathrm{m}$ reflectance as a function of $11.0-\mu \mathrm{m}$ brightness temperature, (b) $1.64-\mu \mathrm{m}$ reflectance as a function of 11.0 - $\mu \mathrm{m}$ brightness temperature and $0.65-\mu \mathrm{m}$ reflectance as a function of $11.0-\mu \mathrm{m}$ brightness temperature. (c) BTD $(3.78-11)$ as a function of $11.0-\mu \mathrm{m}$ brightness temperature, and (d) BTD $(8.52-11)$ as a function of $11.0-\mu \mathrm{m}$ brightness temperature. The RT calculations are performed assuming a cirrus cloud at $T=230 \mathrm{~K}$ using a climatological midlatitude summer temperature and humidity profile to calculate atmospheric absorption, given solar zenith, viewing zenith, and relative azimuth angles of $30^{\circ}, 20^{\circ}$, and $140^{\circ}$, respectively.

both the size and habit distributions than at the shorter wavelengths. At $1.64 \mu \mathrm{m}$, all three models show an increase in $\omega_{o}$ when the number of size bins is increased from 5 to 27 . This is also the trend for the FIRE-II and ARM cases at 2.13 and $3.78 \mu \mathrm{m}$, although the trend is reversed for the FIRE-I case. At 1.64, 2.13, and 3.78 $\mu \mathrm{m}$, the $\omega_{0}$ values decrease when the habit distribution is changed from the fixed distribution to the measured distributions for the FIRE-I and FIRE-II models, whereas the values for the ARM model increase. The FIREII models tend to be slightly more sensitive to the discretization of the size bins, and the ARM and FIRE-I 


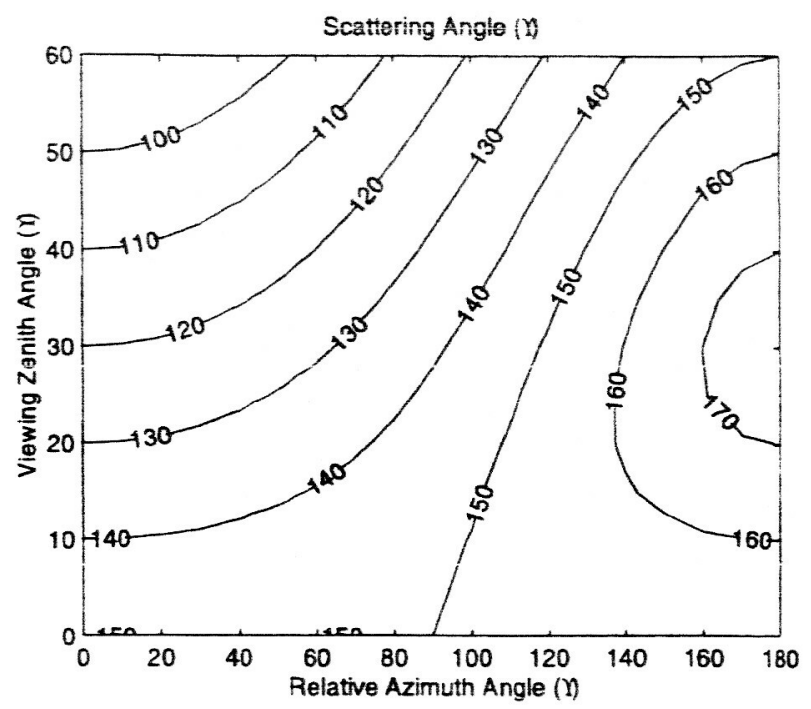

FIG. 9. Scattering angles computed for the RT calculations provided in Figs. 10, 12, and 14.

models are more sensitive to the details of the habit distribution. These sensitivities can be explained to a large degree by the dependence of $\omega_{o}$ on $D_{e}$.

At IR wavelengths, where ice absorption within the crystals is much stronger than at visible or NIR wavelengths, the values for $\omega_{o}$ still show sensitivity both to the assumed ice crystal size and to the habit distributions. The behavior of the $\omega_{o}$ values with respect to changes in wavelength, habit distribution, and number of size bins is similar for the FIRE-II and ARM models but differs for the FIRE-I model. The sensitivity to the discretization of the size bins and to the habit distribution at IR wavelengths is similar to that at the NIR wavelengths. The FIRE-I and ARM modeled $\omega_{o}$ values are more sensitive to the size distributions; the values for the FIRE-II model are more sensitive to the habit distribution.

Scattering phase functions for the FIRE-I, FIRE-II, and ARM cirrus microphysical models are provided in Figs. 4 through 6 , respectively, for MODIS wavelengths $\lambda=0.65,1.64,3.78$, and $11.0 \mu \mathrm{m}$. For the FIRE-I and FIRE-II models, there tends to be little variation at scattering angles greater than $50^{\circ}$ among the three sets of microphysical models, with the largest variations occurring at $3.78 \mu \mathrm{m}$. The phase functions developed for the ARM data tend to display the most variation, primarily due to the prominence of bullet rosettes as the dominant habit and also the prevalence of very large ice crystals.

A comparison of phase functions developed from the use of measured ice crystal habit distributions and a 27 bin size distribution is provided in Fig. 7. This comparison shows that the most variation in the phase function occurs at $3.78 \mu \mathrm{m}$, especially at side-scattering angles.

\section{Radiative transfer results}

Radiative transfer calculations were performed as in Baum et al. (2000) to demonstrate the effects of habit and size distribution on TOA reflectances and brightness temperatures. Results from using a midlatitude summer temperature and humidity profile to compute atmospheric absorption as described in section $2 \mathrm{~d}$ are shown. Although not shown, similar results are obtained when a midiatitude winter profile is used.

Reflectance and brightness temperature difference results, based on FIRE-I cirrus data, are provided in Fig. 8 for solar zenith, viewing zenith, and relative azimuth angles of $30^{\circ}, 20^{\circ}$, and $140^{\circ}$, respectively. The radiative transfer calculations are performed for a cirrus cloud at $T=230 \mathrm{~K}$. Cirrus $0.65-\mu \mathrm{m}$ optical thicknesses vary from 0 to 20 . Figure $8 \mathrm{a}$ shows that the $0.65-\mu \mathrm{m}$ reflectances are not a strong function of either size or habit distributions. However, the $1.64-\mu \mathrm{m}$ reflectances shown in Fig. $8 \mathrm{~b}$ indicate a dependence both on size and habit distribution, and the reflectance differences between the models increase with increasing optical thickness. Figs. $8 \mathrm{c}$ and $8 \mathrm{~d}$ show brightness temperature difference (BTD) results between the 3.78- and $11-\mu \mathrm{m}$ bands [BTD $(3.78-11)$ ] and the $8.5-$ and $11-\mu \mathrm{m}$ bands [BTD (8.511)]. Of interest, the BTD (3.78-11) calculations show more sensitivity to the particle habit and size distributions than do the BTD (8.5-11) results.

The results in Fig. 8 are performed for a specific set of viewing angles and will now be extended to a wider range of viewing angles. As a reference for the following figures, a set of scattering angles is provided in Fig. 9. Figure 10 shows the result of RT calculations performed assuming a cirrus $0.65-\mu \mathrm{m}$ optical thickness of 1 at a constant solar zenith angle of $30^{\circ}$ for the three cirrus microphysical models (see section 3a) derived from the FIRE-I data. The numerical differences of reflectances or brightness temperature differences become more pronounced at higher cirrus optical thicknesses but are not shown here.

Figure 10a shows the percent relative differences in 1.64- $\mu \mathrm{m}$ reflectances between the FIRE-I cirrus model derived using 27 size bins with a measured distribution [section $3 \mathrm{a}(3)$ ] and the cirrus model derived using 27 size bins with fixed habit distribution [section $3 a(2)$ ]. Figure $10 \mathrm{~b}$ shows the percent relative differences in 1.64- $\mu \mathrm{m}$ reflectances for the FIRE-I cirrus models derived using 27 size bins with a fixed distribution [section $3 a(2)]$ and the cirrus model derived using five size bins with fixed habit distribution [section 3a(1)]. The differences in 1.64- $\mu \mathrm{m}$ reflectance shown in Fig. 10a are due primarily to a change in the prescribed habit distribution, whereas the differences in Fig. 10b are due to changing the discretization of the size distribution. The reflectance differences in Fig. 10a and 10b can become appreciable at scattering angles greater than $160^{\circ}$ and at scattering angles less than $120^{\circ}$, even though the cirrus optical thickness is constant at 1 . As the cirrus 
a) $1.64 \mathrm{jim}$

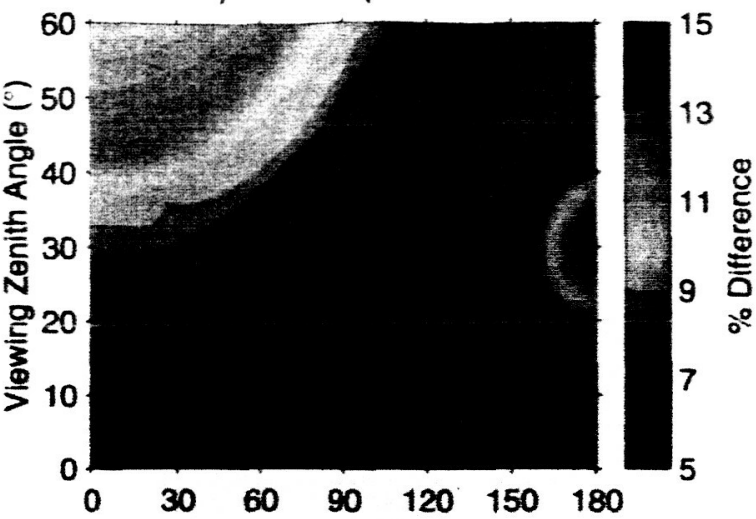

c) $3.78 \mu \mathrm{m}-11 \mu \mathrm{m}$

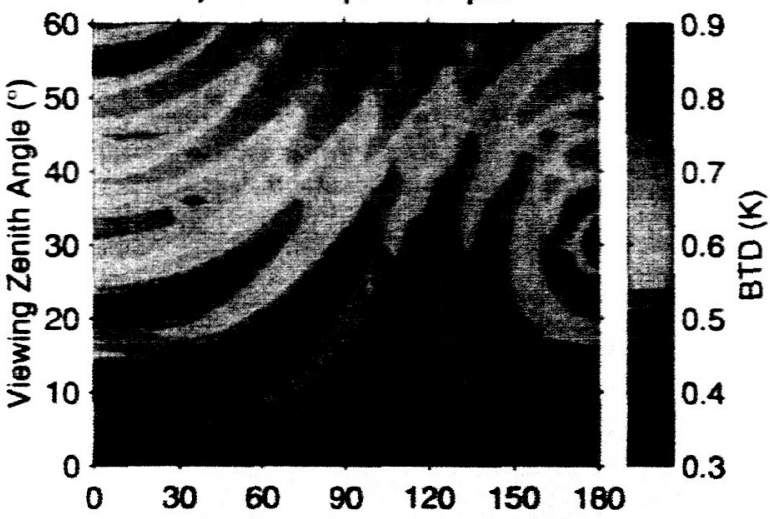

e) $8.5 \mu \mathrm{m}-11 \mu \mathrm{m}$

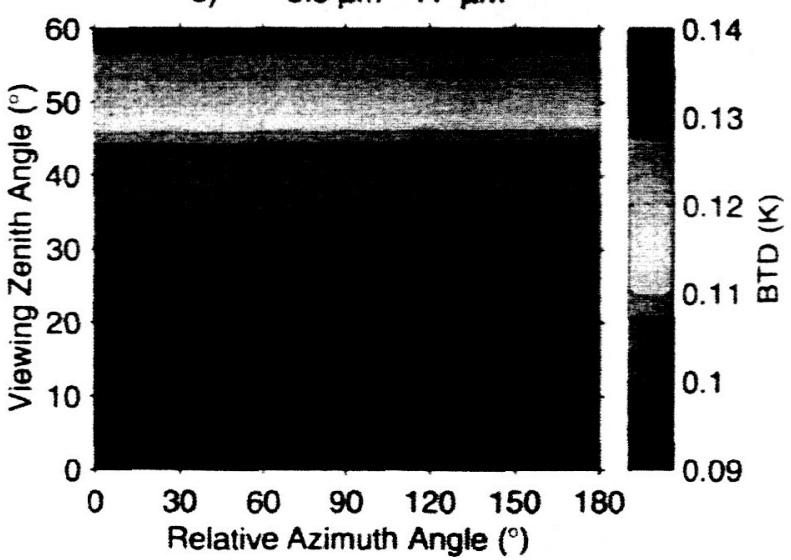

b) $\quad \mathbf{6 . 6 4 \mu \mathrm { m }}$

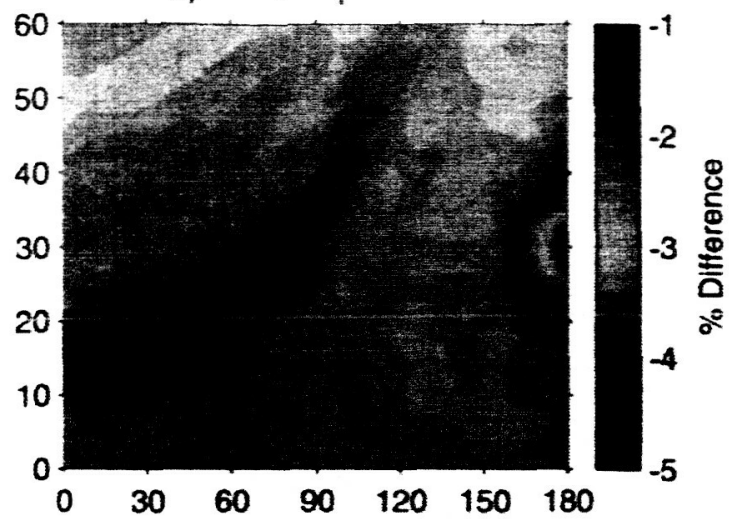

d) $3.78 \mu \mathrm{m}-11 \mu \mathrm{m}$

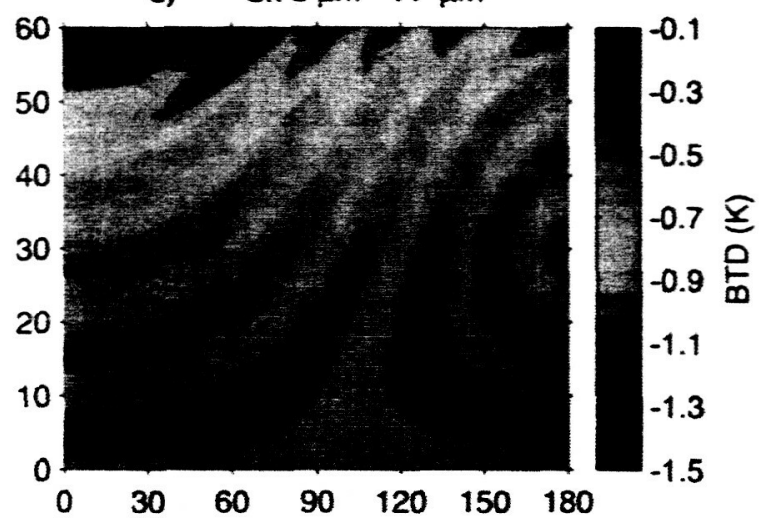

f) $8.5 \mu \mathrm{m}-11 \mu \mathrm{m}$

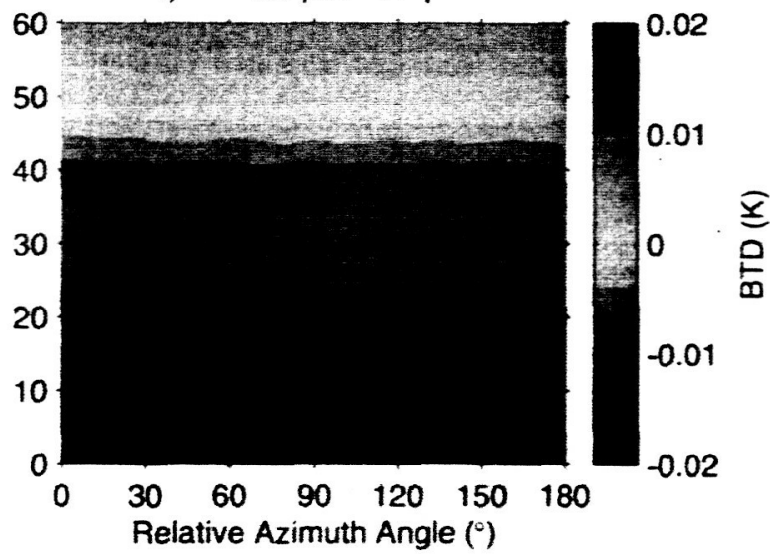

FIG. 10. Relative difference computed using the FIRE-I cirrus microphysical models. Calculations assume a 0.65 - $\mu \mathrm{m}$ optical thickness of 1 , a solar zenith angle of $30^{\circ}$, and a midlatitude summer atmospheric profile.

optical thickness increases, Fig. 8 indicates that the $1.64-\mu \mathrm{m}$ reflectances will show even more sensitivity to the prescribed particle and habit distributions.

Figures $10 \mathrm{c}$ and $10 \mathrm{e}$ show the differences (in kelvin) in the BTD (3.78-11) and BTD (8.5-11) values calculated for the FIRE-I cirrus model derived using 27 size bins with a measured habit distribution [section
$3 a(3)]$ and the cirrus model derived using 27 size bins with fixed habit distribution [section $3 \mathrm{a}(2)$ ]. The differences in BTD (3.78-11) and BTD (8.5-11) are relatively small over the prescribed range in scattering angles. Examination of Fig. 8 supports the contention that the BTD (3.78-11) differences are expected to become more pronounced at higher cirrus optical thicknesses. 
a)

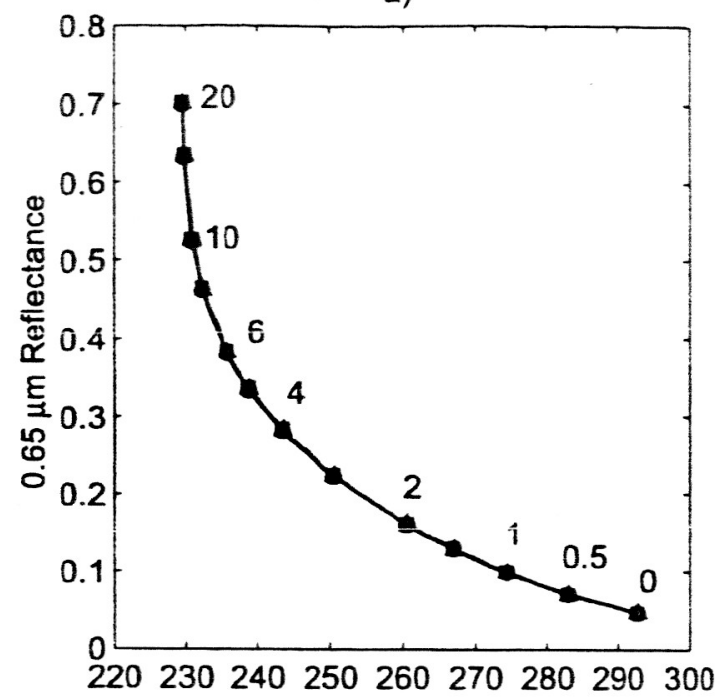

c)

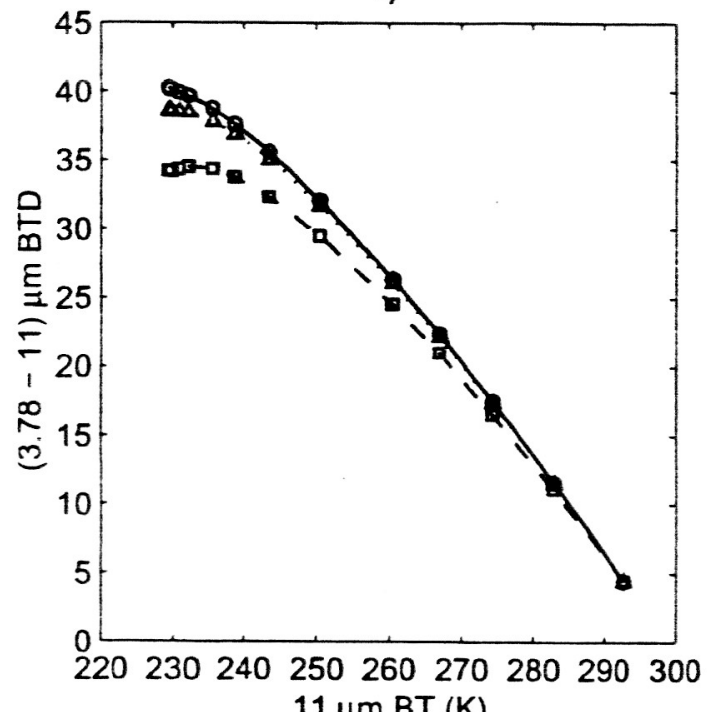

b)

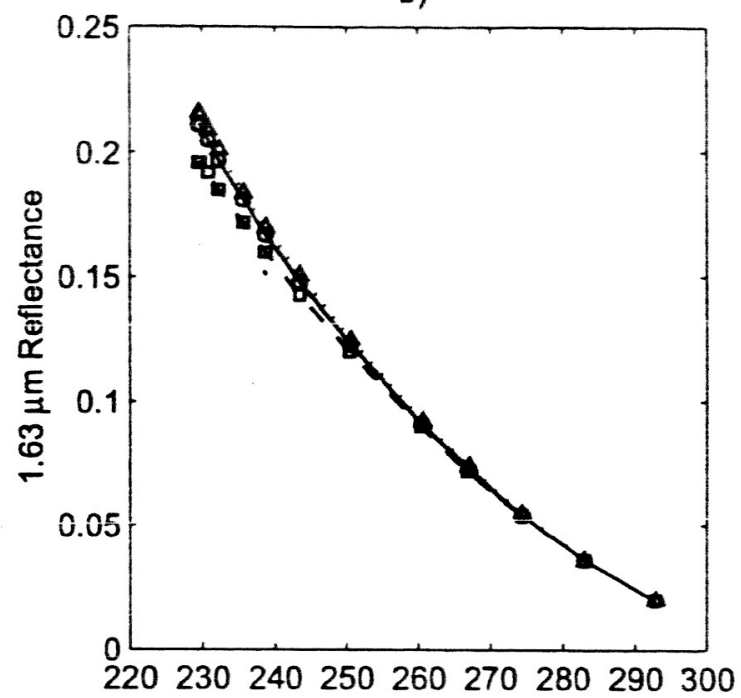

d)

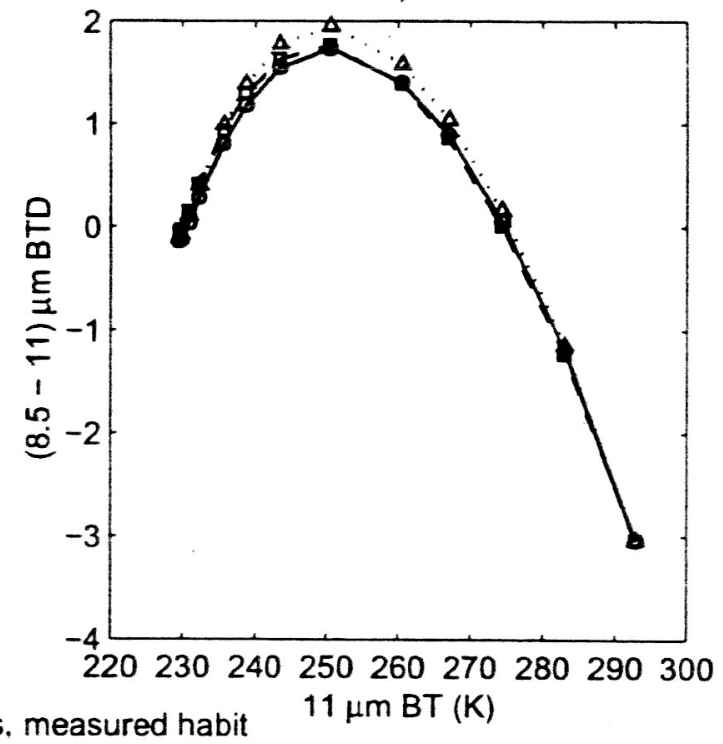

$\triangle 27$ size bins, fixed habit

$\rightarrow-5$ size bins, fixed habit

Fig. 11. As in Fig. 8, but using cirrus microphysical models based on FIRE-II data.

Figures $10 \mathrm{~d}$ and $10 \mathrm{f}$ show the differences (in kelvin) in the BTD (3.78-11) and BTD (8.5-11) values calculated for the FIRE-I cirrus model derived using 27 size bins with a fixed habit distribution [section 3a(2)] and the cirrus model derived using five size bins with fixed habit distribution [section 3a(1)]. Here the differences in BTD (3.78-11) and BTD (8.5-11) are due primarily to a change in the discretization of the particle size distribution. The BTD (3.78-11) differences are typically less than $0.8 \mathrm{~K}$ at viewing zenith angles less than $40^{\circ}$. The BTD $(8.5-11)$ differences are typically less than $0.1 \mathrm{~K}$ at viewing zenith angles less than $40^{\circ}$.

Figure 11 shows results similar to those in Fig. 9 but for the FIRE-II data. The calculations are performed for a cirrus cloud at $T=230 \mathrm{~K}$ using a climatological midlatitude summer profile. As with the FIRE-I results, Fig. 11a shows that the $0.65-\mu \mathrm{m}$ reflectances are not a strong function of either the assumed size or habit dis- 
a) $1.64 \mu \mathrm{m}$

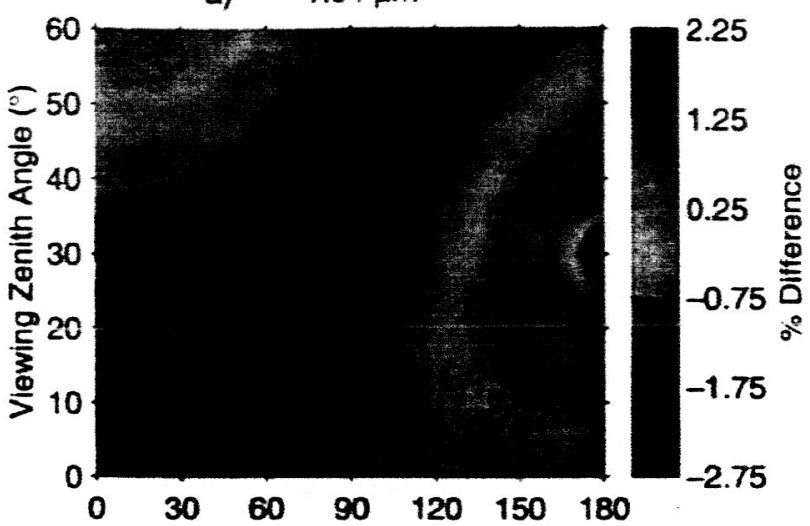

c) $\quad 3.78 \mu \mathrm{m}-11 \mu \mathrm{m}$

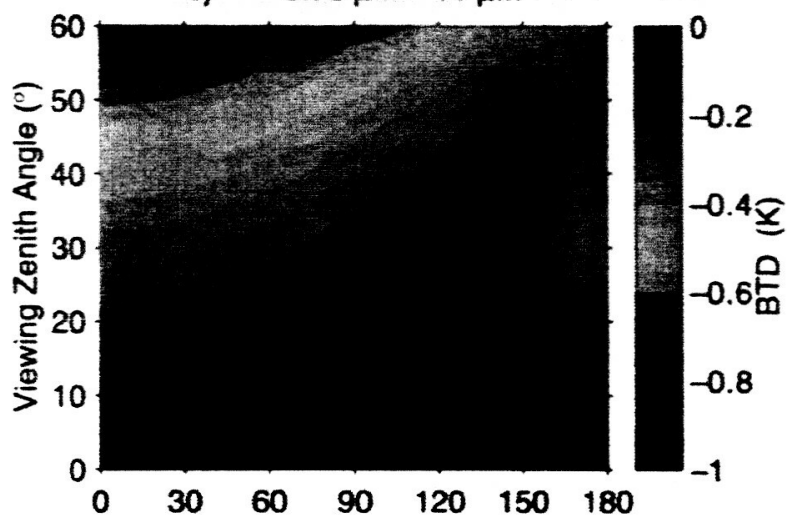

e) $8.5 \mu \mathrm{m}-11 \mu \mathrm{m}$

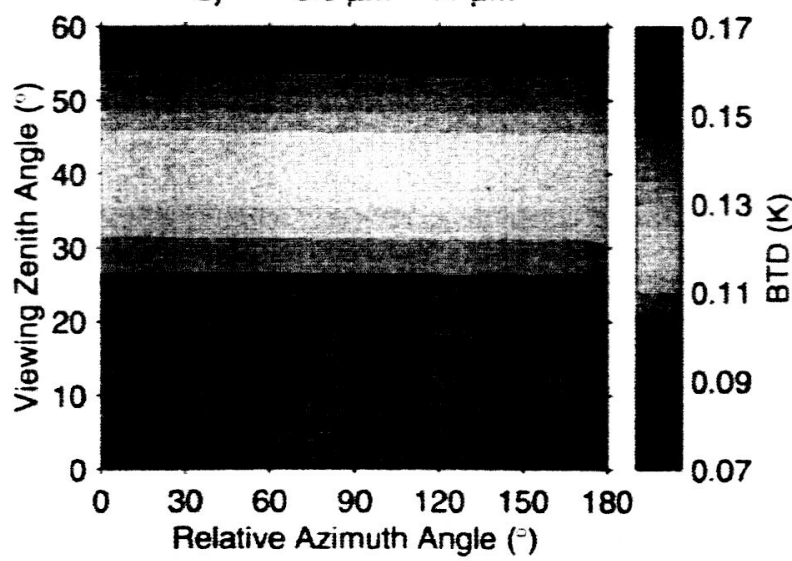

b) i.64 um

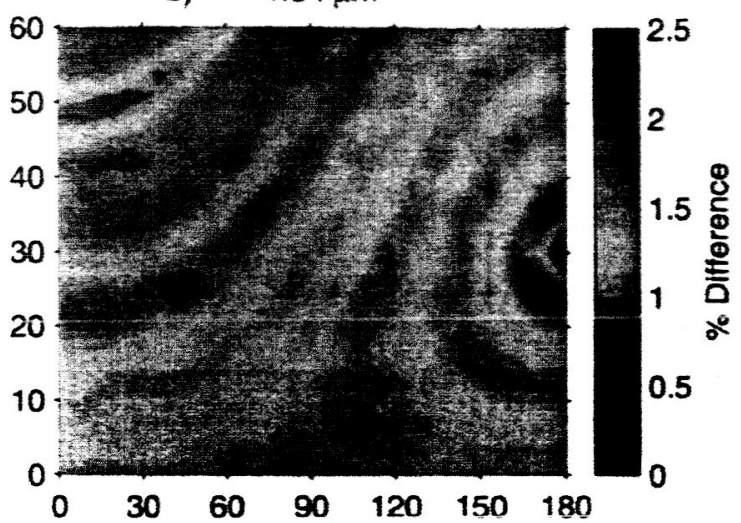

d) $3.78 \mu \mathrm{m}-11 \mu \mathrm{m}$

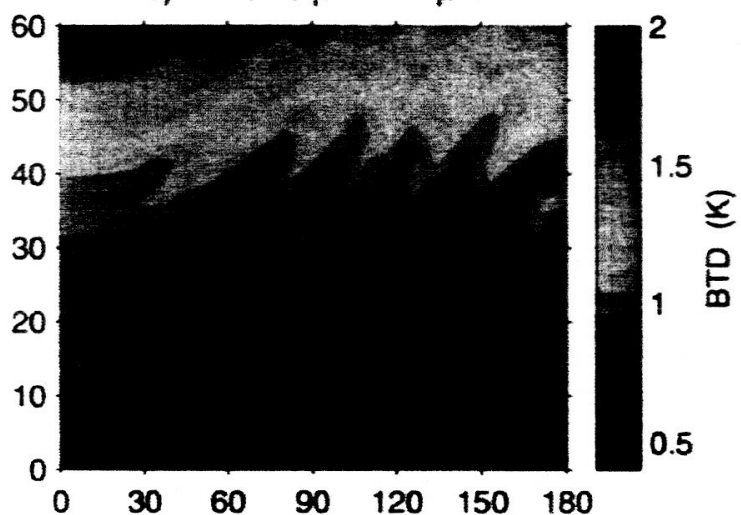

f) $8.5 \mu \mathrm{m}-11 \mu \mathrm{m}$

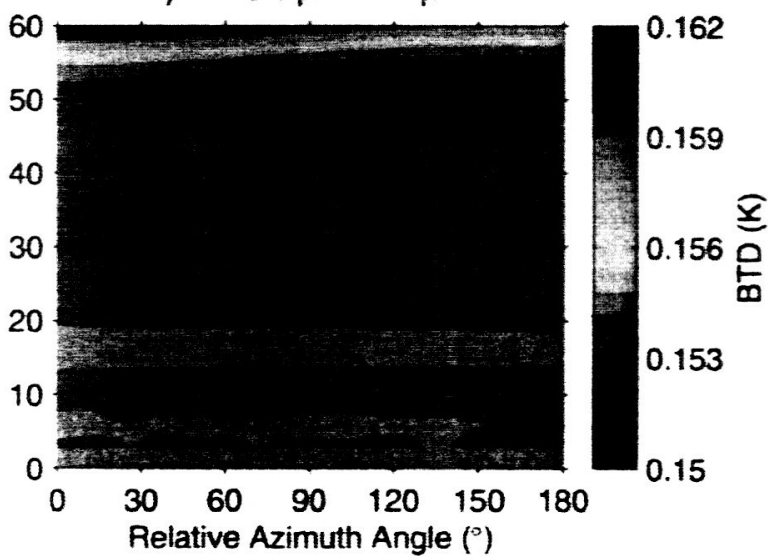

FIG. 12. Relative difference computed using the FIRE-II cirrus microphysical models. Calculations assume a $0.65-\mu m$ optical thickness of 1, a solar zenith angle of $30^{\circ}$, and a midlatitude summer atmospheric profile.

tribution. However, the $1.64-\mu \mathrm{m}$ reflectances shown in Fig. $11 \mathrm{~b}$ indicate a slight dependence both on size and habit distribution at higher cloud optical thicknesses. The effect is less pronounced for the FIRE-II data than for the FIRE-I data. Figures $11 \mathrm{c}$ and $11 \mathrm{~d}$ show brightness temperature difference results for BTD (3.78-11) and the BTD (8.5-11), respectively, as a function of the
11- $\mu \mathrm{m}$ brightness temperature. The BTD (3.78-11) calculations show more sensitivity to the particle size distribution than to the habit distribution. The BTD (8.511) results indicate less sensitivity to changes in size or habit distribution than with BTD (3.78-11).

Figure 12 shows similar results to Fig. 10 but for the FIRE-II data. Figures $12 \mathrm{a}, 12 \mathrm{c}$, and $12 \mathrm{e}$ show the 
a)

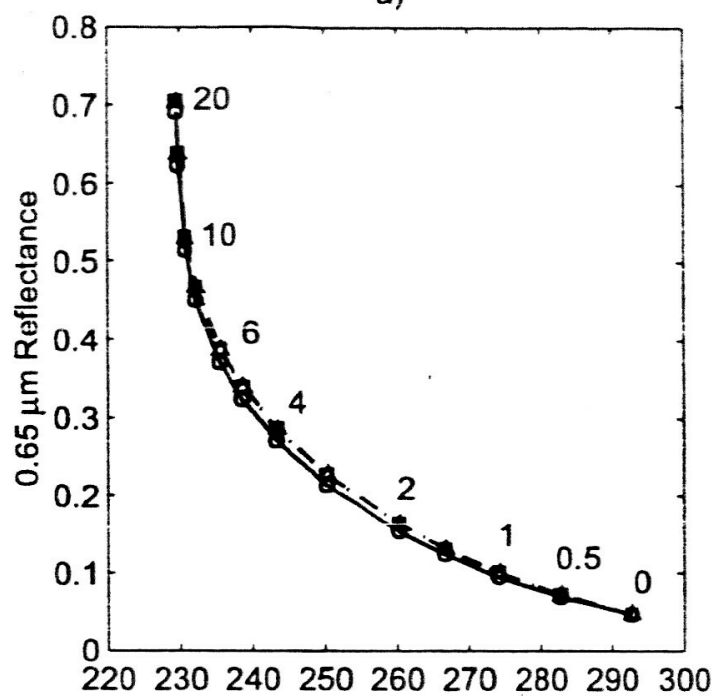

c)

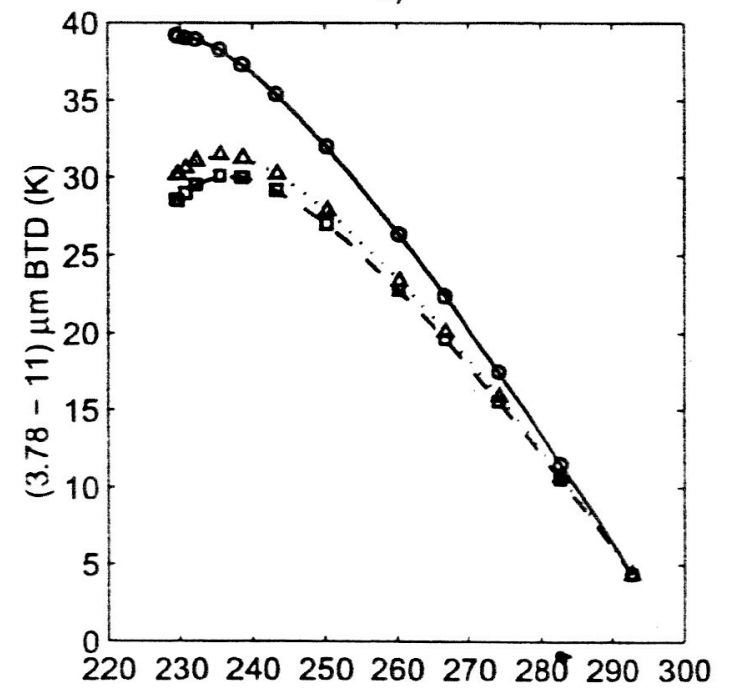

b)

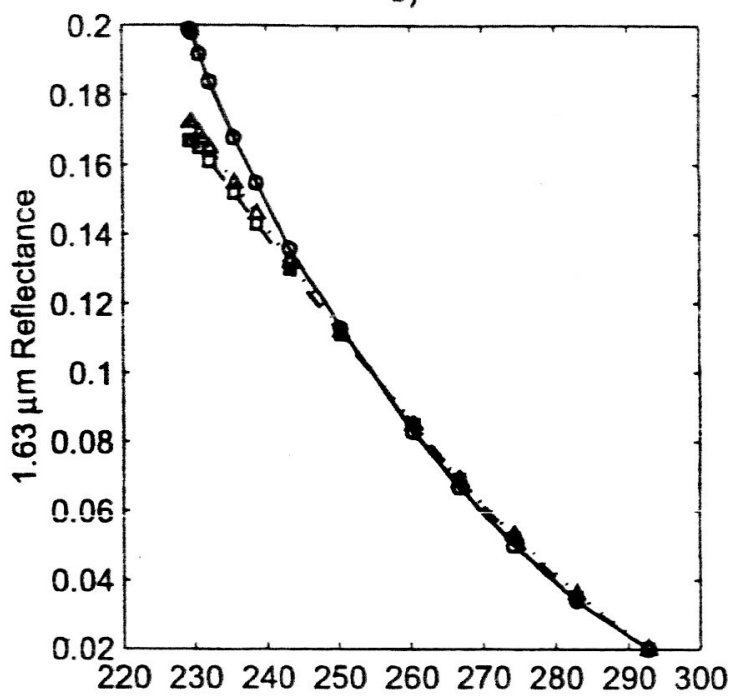

d)

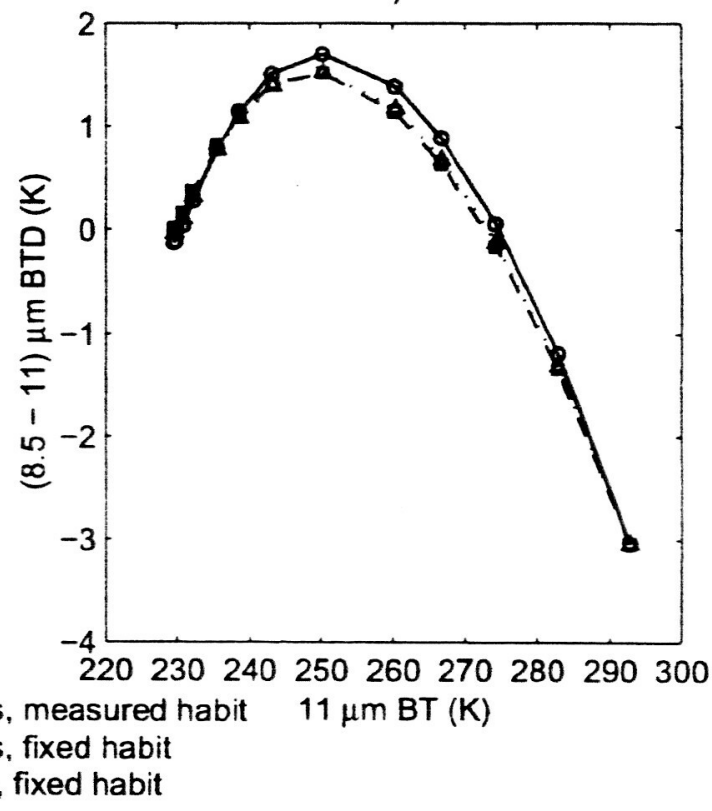

FIG. 13. As in Fig. 8, but using cirrus microphysical models based on ARM IOP data.

differences between the two cirrus models that each have 27 size bins but different habit distributions, whereas Figs. 12b, 12d, and 12f show the differences between the cirrus models that have the same habit distribution but a different number of size bins describing their size distributions. The $1.64-\mu \mathrm{m}$ reflectances are not strongly influenced by changes in the habit distribution over a range of scattering angles, with reflectances generally within $3 \%$ of each other. The BTD (3.78-11) show slightly more dependence on the size distribution than on the habit distribution. For the FIRE-II data, the BTD (3.78-11) values are more sensitive to both size and habit distribution than are the BTD(8.52-11) values.

Figure 13 shows results similar to those in Figs. 8 and 11 but for the ARM IOP data. The calculations are performed for a cirrus cloud at $T=230 \mathrm{~K}$ using a climatological midlatitude summer profile. As with the FIREI and FIRE-II results, Fig. 13a shows that the $0.65-\mu \mathrm{m}$ reflectances are not a strong function of either the as- 
a) $1.64 \mathrm{im}$

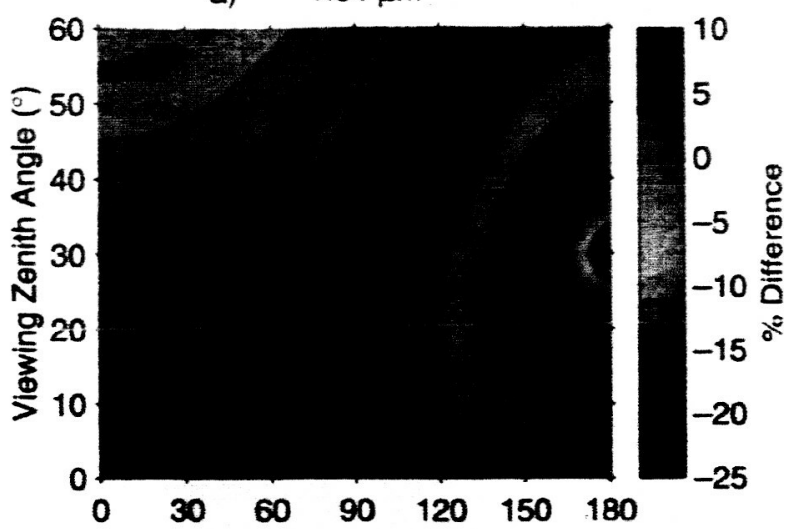

c) $3.78 \mu \mathrm{m}-11 \mu \mathrm{m}$

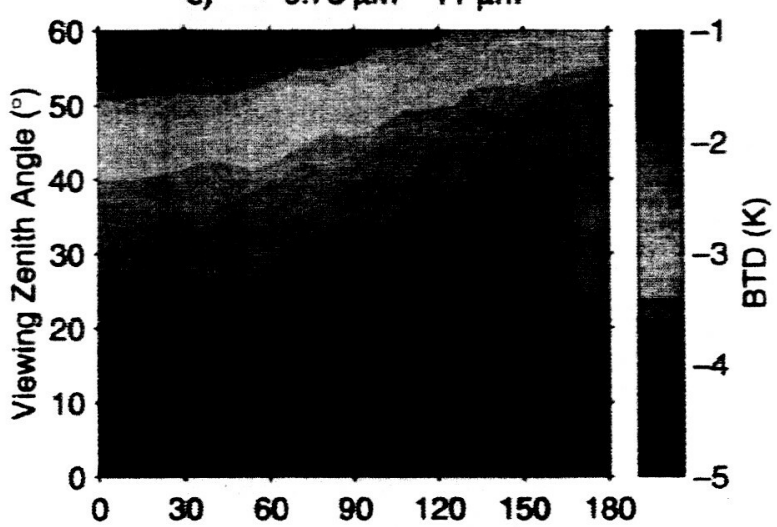

e) $8.5 \mu \mathrm{m}-11 \mu \mathrm{m}$

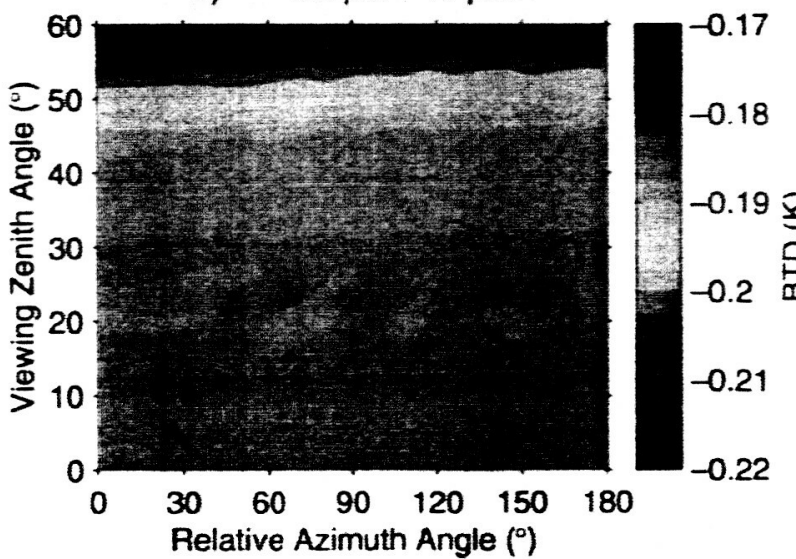

b) $\quad 1.64 \mu \mathrm{m}$

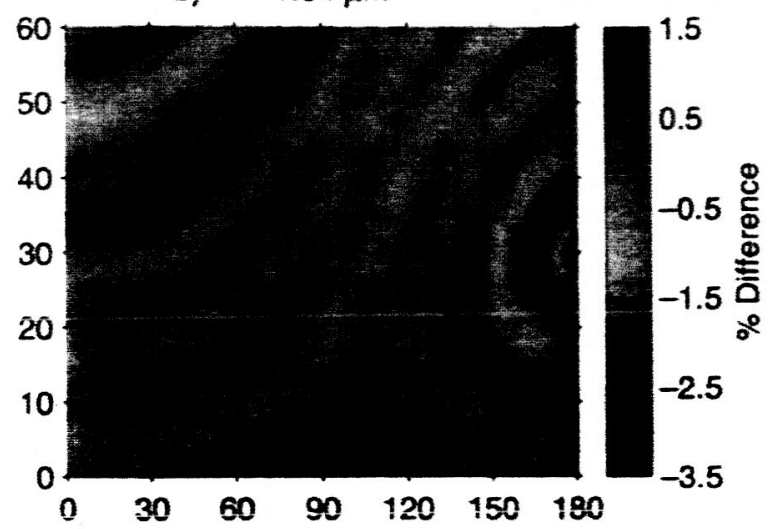

d) $3.78 \mu \mathrm{m}-11 \mu \mathrm{m}$

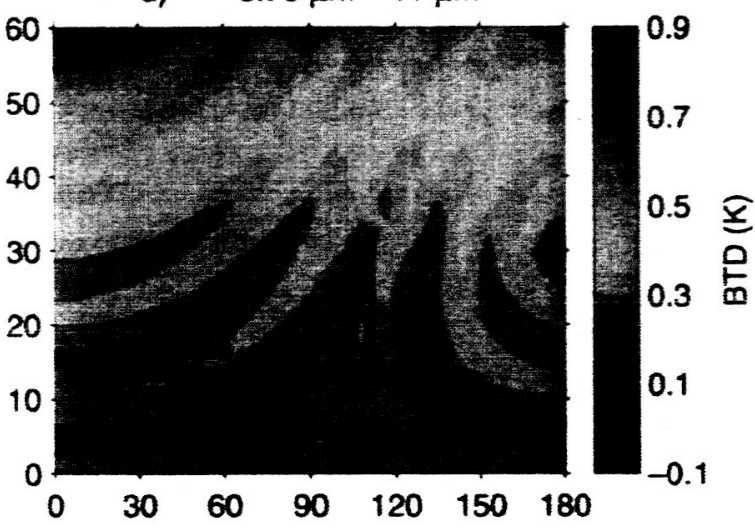

f) $8.5 \mu m-11 \mu m$

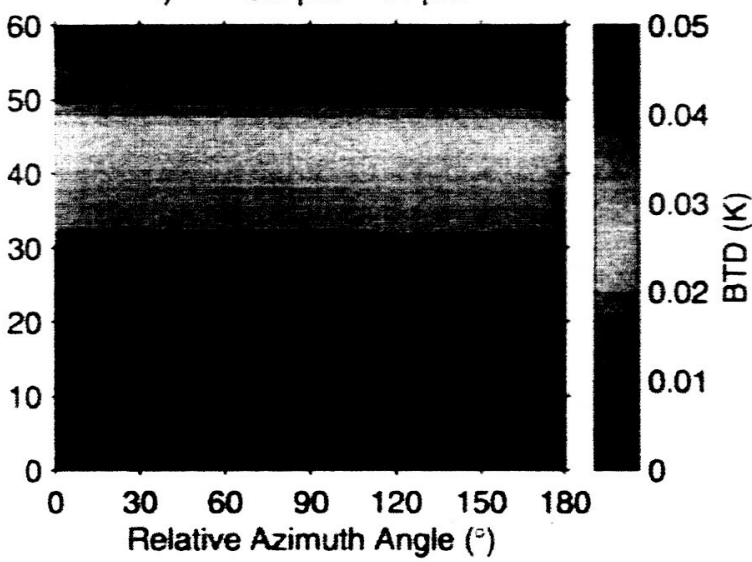

Fig. 14. Relative difference computed using the ARM cirrus microphysical models. Calculations assume a $0.65-\mu m$ optical thickness of 1 , a solar zenith angle of $30^{\circ}$, and a midlatitude summer atmospheric profile.

sumed size or habit distribution. The $1.64-\mu \mathrm{m}$ reflectances shown in Fig. $13 \mathrm{~b}$ indicate a slight dependence both on size and habit distribution at higher cloud optical thicknesses. Figures $13 \mathrm{c}$ and $13 \mathrm{~d}$ show results for BTD (3.78-11) and BTD (8.5-11), respectively, as a function of the $11-\mu \mathrm{m}$ brightness temperature. The BTD (3.7811) calculations show more sensitivity to the particle hab- it distribution than to the size distribution. The main feature of the ARM data is that the predominant habit was bullet rosettes at all levels in the cloud. The bullet rosettes have a relatively low volume-to-area ratio when compared with other crystal habits such as plates or columns. The BTD (8.5-11) results indicate little sensitivity to changes in size or habit distribution. The most sensitivity 
is shown in a relatively narrow range of optical thicknesses ranging from 0.5 to 3 .

Figure 14 shows results similar to those in Figs. 10 and 12 but for the ARM IOP data. The $1.64-\mu \mathrm{m}$ reflectances show markedly more sensitivity to the change in habit distribution (Fig. 14a) than to the size distribution (Fig. 14b). For the ARM IOP data, the 1.64- $\mu \mathrm{m}$ reflectances are influenced more by the size distribution than by changes in the habit distribution. The effect of using measured habit distributions (Figs. 14c,e) rather than the fixed habit distribution tends to lower both the BTD (3.78-11) and the BTD (8.5-11) values. The opposite tendency is noted in Figs. 14d and $14 \mathrm{f}$ when the number of size bins increases from 5 to 27 while keeping the habit distribution fixed.

\section{Summary and conclusions}

Detailed in situ data from cirrus clouds have been collected during dedicated field campaigns, but the use of the size and habit distribution data has been lagging in the development of more realistic cirrus scattering models. In this study, we examine the use of in situ cirrus data collected during three field campaigns to develop more complex and, it is hoped, more realistic cirrus microphysical models. Data are examined from two FIRE campaigns (held in 1986 and 1991) and a recent ARM IOP campaign (held in 1999). All three field campaigns were held in the central United States.

The new cirrus microphysical models form the basis for the development of bulk scattering properties such as single-scatter albedo, extinction coefficients, and scattering phase functions for wavelengths corresponding to a set of MODIS visible, near-infrared, and infrared bands ranging from 0.65 to $12 \mu \mathrm{m}$. The sensitivity of the resulting scattering properties to the underlying assumptions of the assumed particle size and habit distributions are examined. Our results indicate that the effective diameter calculated from a given size distribution tends to be sensitive to the number of size bins that are used to discretize the data and also that the icecrystal habit distribution can play an important role.

To derive a set of midlatitude cirrus models, our approach is to reexamine in situ data from a variety of midlatitude cirrus cases for vertical distributions of particle size and particle habit. Although this is a timeconsuming effort, it offers a firm basis upon which to derive scattering properties. Several questions arise as to our approach. How many individual cirrus cases are necessary to obtain a representative sample for each type of cirrus? Does it make more sense to use cloud-top temperature as a defining factor to define a set of cirrus models or the origin of the cirrus? If one were to adopt a certain cirrus microphysical model upon which to derive a set of scattering properties over a range of wavelengths, would the retrieved cirrus properties be consistent no matter which wavelengths were used to infer the properties? Because we did not try to account for the potential underrepresentation of smail crystais by the 2D-C probes for the FIRE-I and ARM cases, the extinction coefficient may be underestimated. This possibility raises questions regarding the effects of including parameterizations of small crystals in the size distributions.

One way to test the consistency of results using different satellite imagers would be to derive cirrus scattering models in a similar fashion as that presented in this study for other satellite imagers such as the Geostationary Operational Environmental Satellite (GOES), Advanced Very High Resolution Radiometer (AVHRR), the Multiangle Imaging Spectroradiometer, and the Geostationary Imaging Fourier Transfer Spectrometer, which will provide infrared wavelength remote sensing of cirrus. For pairs of these satellites, such as GOES and AVHRR or GOES and MODIS, one can retrieve cirrus properties for the scene where the data for each imager are taken within minutes of each other. If the retrieved cirrus properties are consistent across the wavelength spectrum offered by these and other instruments, it would provide some evidence that a set of cirrus models derived in such a fashion is representative of midlatitude cirrus.

As a result of the research presented in this study, we are now reanalyzing cirrus in situ data from other field campaigns to build microphysical and radiative models for convective systems, tropical cirrus, and polar cirrus. Further efforts will be directed toward the development of a suite of cirrus models that can be applied appropriately to any type of ice-cloud system for global satellite data analysis.

Acknowledgments. This work was funded in part by the ARM Program sponsored by the U.S. DOE under Contract DE-AI02-00ER62901, by NASA/EOS under Contract S-97894-F, by the NASA Radiative Sciences Program managed by Dr. Don Anderson (RR-0000-60), and by a grant from the MODIS Science Team.

\section{REFERENCES}

Baran, A. J., P. D. Watts, and P. N. Francis, 1999: Testing the coherence of cirrus microphysical and bulk properties retrieved from dual-viewing multispectral satellite radiance measurements. J. Geophys. Res., 104, 31 673-31 683.

Baum. B. A., D. P. Kratz, P. Yang, S. Ou, Y. Hu, P. F. Soulen, and S-C. Tsay, 2000: Remote sensing of cloud properties using MODIS Airborne Simulator imagery during SUCCESS. I. Data and models. J. Geophys. Res., 105, $11767-11780$.

Doutriaux-Boucher, M., J.-C. Buriez, G. Brogniez, L. Labonnote, and A. J. Baran, 2000: Sensitivity of retrieved POLDER directional cloud optical thickness to various ice particle models. Geophys. Res. Lett., 27, 109-112.

Foot, J. S., 1988: Some observations of the optical properties of clouds: II Cirrus. Quart. J. Roy. Meteor. Soc., 114, 145-164.

Francis, P. N., A. Jones, R. W. Saunders, K. P. Shine, A. Slingo, and Z. Sun., 1994: An observational and theoretical study of the radiative properties of cirrus: Some results from ICE' 89 . Quart. J. Roy. Meteor. Soc., 120, 809-848.

_ J. S. Foot, and A. J. Baran, 1999: Aircraft measurements of 
the solar and infrared radiative properties of cirrus and their dependence on ice crystal shape. J. Geophys. Res., 104, 31 68531695

Heymsfield, A. J., 1975: Cirrus uncinus generating cells and the evolution of cirroform clouds. Part I: Aircraft observations of the growth of the ice phase. J. Atmos. Sci., 32, 799-808.

_, and C. M. R. Platt, 1984: A parameterization of the particle size spectrum of ice clouds in terms of the ambient temperature and the ice water content. J. Atmos. Sci., 41, 846-855.

- , and L. M. Miloshevich, 1995: Relative humidity and temperature influences on cirrus formation and evolution: Observations from wave clouds and FIRE-II. $J$. Atmos. Sci., 52, 4302-4326.

- K. M. Miller, and J. D. Spinhirne, 1990: The 27-28 October 1986 FIRE IFO Cirrus Case Study: Cloud microstructure. Mon Wea. Rev., 118, 2313-2328.

Knap, W. H., M. Hess, P. Stamnes, and R. B. A. Koelemeijer, 1999. Cirrus optical thickness and crystal size retrieval from ATSR-2 data using phase functions of imperfect hexagonal ice crystals. J. Geophys. Res., 104, 31 721-31 730.

Kratz, D. P., 1995: The correlated $k$-distribution technique as applied to the AVHRR channels. J. Quant. Spectrosc. Radiat. Transfer, 53, 501-517.

Lacis, A. A., and V. Oinas, 1991: A description of the correlated $k$ distribution method for modeling nongray gaseous absorption, thermal emission and multiple scattering in vertically inhomogeneous atmospheres. J. Geophys. Res., 96, 9027-9063.

Macke, A., J. Mueller, and E. Raschke, 1996: Single scattering properties of atmospheric ice crystals. J. Atmos. Sci., 53, 2813-2825.

Miloshevich, L. M., and A. J. Heymsfield, 1997: A balloon-borne continuous cloud particle replicator for measuring vertical profiles of cloud microphysical properties: instrument design, performance, and collection efficiency analysis. J. Atmos. Oceanic Technol., 14, 753-768.

Mishchenko, M. I., W. B. Rossow, A. Macke, and A. A. Lacis, 1996 Sensitivity of cirrus cloud albedo, bidirectional reflectance and optical thickness retrieval accuracy to ice particle shape. $J$. Geophys. Res., 101, 16 973-16985.

Rolland, P., K. N. Liou, M. D. King, S. C. Tsay, and G. M. McFarquhar, 2000: Remote sensing of optical and microphysical properties of cirrus clouds using moderate-resolution imaging spectroradiometer channels: Methodology and sensitivity to physical assumptions. J. Geophys. Res., 105, 11 721-11 738.

Sassen, K., N. C. Knight, Y. Takano, and A. J. Heymsfield, 1994: Effects of ice-crystal structure on halo formation: Cirrus cloud experimental and ray-tracing modeling studies. Appl. Opt., 33, 4590-4601.

Volkovitskiy, O. A., L. N. Pavlova, and A. G. Petrushin, 1980: Scaitering of light by ice crystals. Atmos. Ocean. Phys., 16, 90-102.

Wiscombe, W. J., and J. W. Evans, 1977: Exponential-sum fitting of radiative transmission functions. J. Comp. Phy., 24, 416-444.

Wyser, K., and P. Yang, 1998: Average ice crystal size and bulk shortwave single-scattering properties of cirrus clouds. Atmos. Res., 49, 315-335.

Yang, P., and K. N. Liou, 1996a: Finite-difference time domain method for light scattering by small ice crystals in three-dimensional space. J. Opt. Soc. Amer. A., 13, 2072-2085.

, and $\longrightarrow, 1996 \mathrm{~b}$ : Geometric-optics-integral-equation method for light scattering by nonspherical ice crystals. Appl. Opt., 35, 6568-6584. 